\title{
Chapter
}

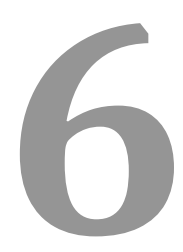

\section{PLASMA SURFACE FUNCTIONALIZATION OF BIODEGRADABLE ELECTROSPUN SCAFFOLDS FOR TISSUE ENGINEERING APPLICATIONS}

Rouba Ghobeira, Nathalie de Geyter, and Rino Morent*

Research Unit Plasma Technology (RUPT), Department of Applied Physics, Faculty of Architecture and Engineering, Ghent University, Ghent, Belgium 


\section{Contents}

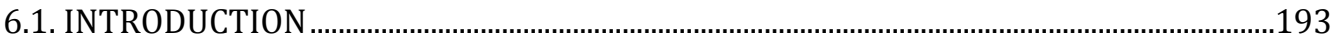

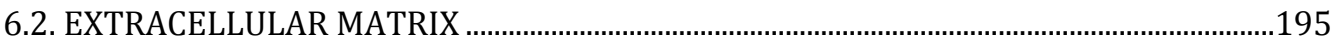

6.3. NATURAL ECM-DERIVED COMPONENTS USED IN TE APPLICATIONS .........................197

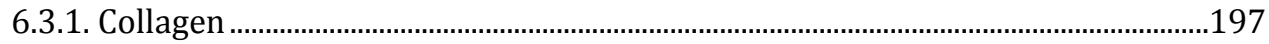

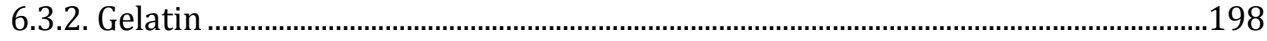

6.3.3. Laminin.............................................................................................................................198

6.4. SYNTHETIC BIODEGRADABLE POLYMERS USED IN TE APPLICATIONS..........................199

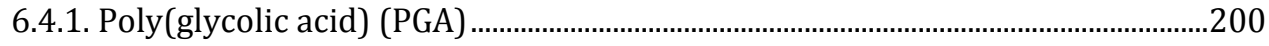

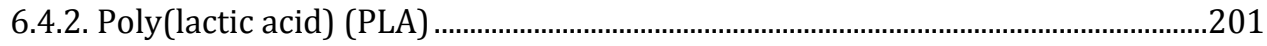

6.4.3. Poly(lactic-co-glycolic acid) (PLGA) ……………………………………………....2202

6.4.4. Polycaprolactone (PCL)...........................................................................................203

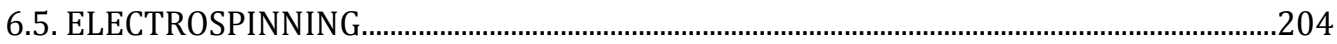

6.5.1. Concept and mechanism of electrospinning ........................................................2205

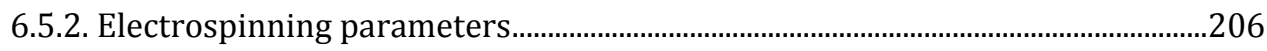

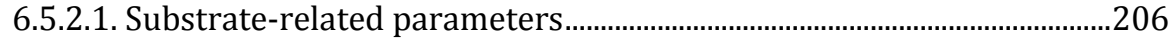

6.5.2.2. Process-related parameters................................................................................208

6.6. DIFFERENT FUNCTIONALIZATION APPROACHES OF ELECTROSPUN BIODEGRADABLE POLYMERS.............................................................................................209

6.7. PLASMA-ASSISTED SURFACE FUNCTIONALIZATION OF NANOFIBERS ........................213

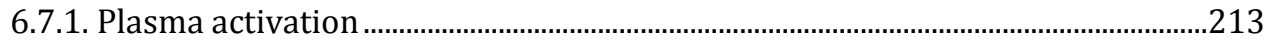

6.7.2. Plasma-activated nanofibers in TE applications...................................................216

6.7.2.1. PCL fibers ......................................................................................................22

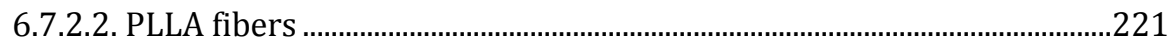

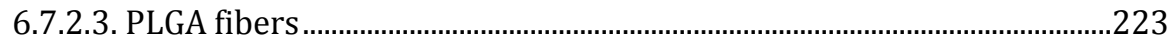

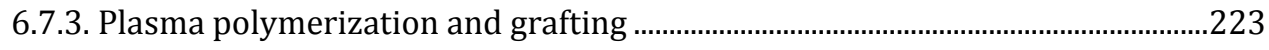

6.7.4. Plasma polymerization and grafting applied on nanofibers in TE

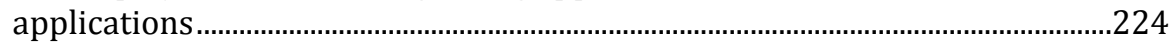

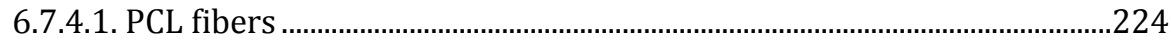

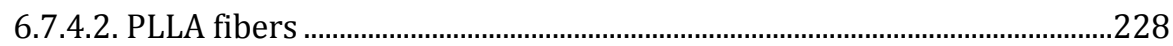

6.7.4.3. PLGA fibers ..........................................................................................................231

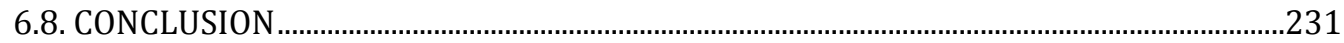

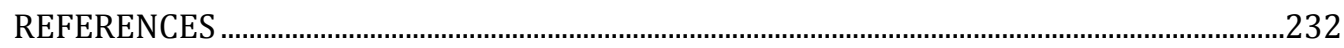




\subsection{INTRODUCTION}

Tissue engineering (TE) represents a rapidly evolving research area overcoming the limitations of conventional transplantation methods and holding promises to revolutionize the quality of life of patients suffering failure or loss of organs and tissues [1]. The concept of engineering human tissues was first coined in 1987 by Dr. Fung at the National Science Foundation (NSF) workshop [2]. During the same workshop of the subsequent year, the term "tissue engineering" was described as the application of the methods and principles of life sciences and engineering to understand the relationships between the structure and the function in pathological and novel tissues and the development of substitutes for the restoration, maintenance and improvement of tissue functions [3]. However, it was until 1993, when Langer and Vacanti wrote their world-shattering paper about TE and its possibilities, that the scientific community began its investigations [4]. The collective effort of biologists, engineers, chemists, material scientists and clinicians has led to phenomenal advances in the regeneration of almost all tissue types. Four TE approaches are being adopted to achieve this goal: 1) the transplantation or injection of isolated cells that can be manipulated via gene therapy to help tissue regeneration, 2) the use of a biomaterial membrane as scaffold to promote the regeneration, 3) the use of scaffolds combined with bioactive factors and 4) the use of scaffolds in combination with cells with or without biological molecules [5]. Scaffold-based approaches (Figure 1) are nowadays gaining a huge popularity due to the potential of novel technologies to provide the scaffolds with adequate chemical, physical and biological cues ensuring a harmonized interaction between the cells and the material. The requirements that must be fulfilled by the scaffolds are the following:

- Biodegradability which is often a fundamental prerequisite eliminating the need of a surgical intervention to remove the implant. Therefore, natural and synthetic biodegradable polymers have gained a widespread interest in the TE field since they are chosen to be the basic materials for the fabrication of most of the scaffolds. The selection of appropriate polymers is important in every specific application since their degradation rate should coincide with the tissue regeneration rate to support but also provide room for tissue formation and neovascularization $[6,7]$.

- Non-toxicity of the material and its degradation products that should not provoke any genotoxicity or immunogenicity [8].

- Possession of mechanical properties matching those of the neighboring tissues and making the selection of suitable polymers more challenging [9]. 
- Mimicry of the extracellular matrix (ECM) which is a primordial factor for effective cell-material interactions.

In the body, a wide range of vital cellular activities such as adhesion, proliferation, migration, gene expression and differentiation, is governed by the ECM/cells interactions [7]. The fibrillary nanostructure of the ECM was thought to be the only factor modulating some of the cellular activities. However, many studies have shown that the ECM components provide biochemical cues necessary for cell signaling and tissue morphogenesis [10]. Therefore, the more closely the scaffold mimics the ECM physical arrangement and biochemical properties, the more successful is the tissue regeneration process. Researchers were able to develop several techniques in order to recreate the ECM architecture. Among them electrospinning is the most broadly used since it creates nanofibers in a very practical and affordable way [11]. Biochemical cues can be afforded by tailoring the surface chemistry of the electrospun mats to promote the adsorption of proteins and subsequent cell-signaling pathways. To this end, different surface modification techniques have been performed such as ion-beam, X-ray, gamma radiation, wet chemical treatment and plasma-based techniques [12]. Specific bioactive molecules can be grafted onto the surface after modifying its chemistry or can be blended with the polymer solution prior to the electrospinning [13]. Plasma surface engineering of electrospun materials has known an abrupt rise during the past decade due to its potential to selectively modify the surface chemistry with a precise control of all the process parameters to avoid the damage of the delicate nanofibrous structure $[14,15]$. Therefore, this chapter will first briefly describe the ECM architecture and composition in addition to the mechanisms underlying the cell/ECM communications to understand the basis on which the researchers were centered to fabricate tissue-engineered scaffolds. A short review will then be given on the natural and synthetic biodegradable polymers that are commonly used to develop electrospun scaffolds. Thereafter, the theory behind the electrospinning technique will be explained, accompanied with a concise overview on the effects of changing the working parameters on the nanofibers properties. Surface modification of electrospun nanofibers will be discussed, particularly highlighting plasma activation, polymerization and subsequent grafting of bioactive molecules on electrospun polymers. An extensive overview on recent achievements of plasma-functionalized nanofibers mainly used in nerve, bone and cardiovascular TE will be given. 


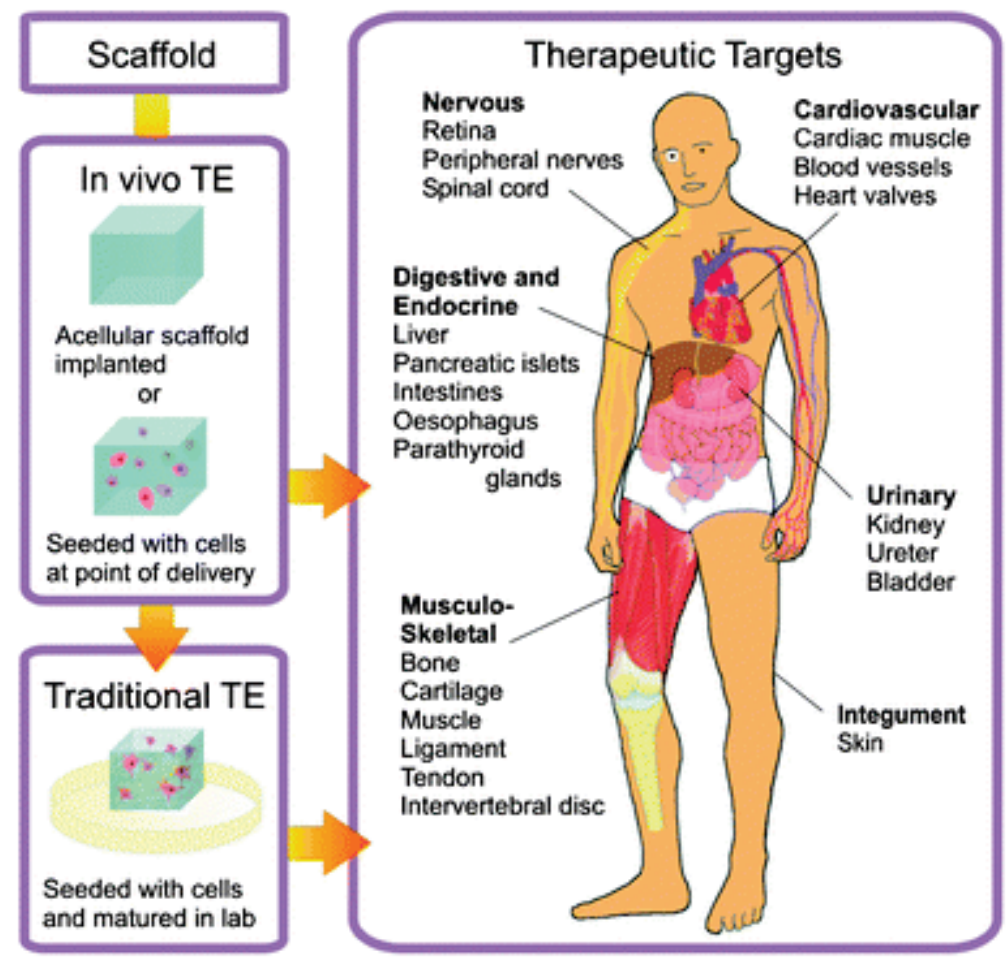

Figure 1. Traditional and in vivo TE approaches. (Traditional TE: in vitro maturation of the cells cultured on the scaffold before being implanted into the patient; In vivo TE: Direct implantation of the scaffold into the patient with or without cells). Reprinted from [16]. Copyright ${ }^{\odot} 2009$ with permission from Royal Society Chemistry.

\subsection{EXTRACELLULAR MATRIX}

The ECM represents the non-cellular constituent of all tissues and organs affording a three-dimensional (3D) scaffolding for the cells, modulating cellcell communication and providing biochemical and physical cues governing a wide range of cellular activities [5]. Many studies have shown its primordial importance in tissue morphogenesis and regeneration which is also clearly illustrated by the numerous diseases arising from genetic defects of its constituents. It is composed of a very complex crosslinked network of fibrillary proteins and glycosaminoglycans (GAGs) generally attached to the ECM proteins to form proteoglycans in which small bioactive molecules such as growth factors are trapped. The fibrous proteins are mainly collagen, laminin, elastin and fibronectin (Figure 2). The classification of the ECM components into structural and functional categories is impossible since most of the studied molecules have synchronic roles $[10,17]$. Concerning the structural role, many in vitro studies have shown that the cells are extremely sensitive to the fibrous 3D architecture and the nanometer length scale offered by the ECM. The 
considerable difference in the behavior of cells cultured on 2D or 3D scaffolds revealed that 2D biomaterials cannot ensure a successful tissue regeneration when implanted in the body [5]. Moreover, cells were shown to respond more efficiently to nanostructured than to microstructured surfaces, they are capable to react with structures as small as $5 \mathrm{~nm}$ [18]. An important role of the ECM is triggering of cellular motility and migration that are critical aspects in tissue regeneration. The cells contain a polymeric network of microtubules, actin and intermediate filaments structurally organized to generate pushing and pulling forces able to move the cells. The interaction between this network and the ECM fibrous network causes a spontaneous succession of depolymerization and polymerization of the cytoskeletal fibers leading to a coordinated cellular motility [6]. The functional role of the ECM, provided by the nonstop cross-talk between cells and biochemical cues of the ECM effectors, can be supported by the highly cell and tissue specific ECM composition that is diverse throughout the body. The binding of specific growth factors to specific ECM components leads to an increase in the stability of the growth factors thus creating an adequate microenvironment regulating cell proliferation and differentiation [5]. Moreover, cellular receptors can recognize specific ECM sites thus mediating the adhesion of the cells to ECM. The main group of cellular receptors is the integrin transmembrane proteins consisting of one $\alpha$ and one $\beta$ subunits. Up until now, around $18 \alpha$ subunits and $8 \beta$ subunits are identified and 24 diverse heterodimers are recognized, each binding to specific ligands within the peptide sequences forming the ECM proteins such as collagen, fibronectin and laminin known as the "ECM glue" [19]. Integrin attachment to ECM ligands provokes a cascade of processes. The actin proteins inside the cell form microfilaments bundles also called stress fibers triggering the formation of focal adhesion which links the actin cytoskeleton to ECM molecules. The focal adhesion structures will initiate several signal transduction pathways in the cells changing their gene expression thus modulating a wide range of cell activities [5,20]. The importance of the biological components in the integrin-mediated cell adhesion and the growth factor attachment has led the tissue engineers to consider the use of natural components in the fabrication of scaffolds. 


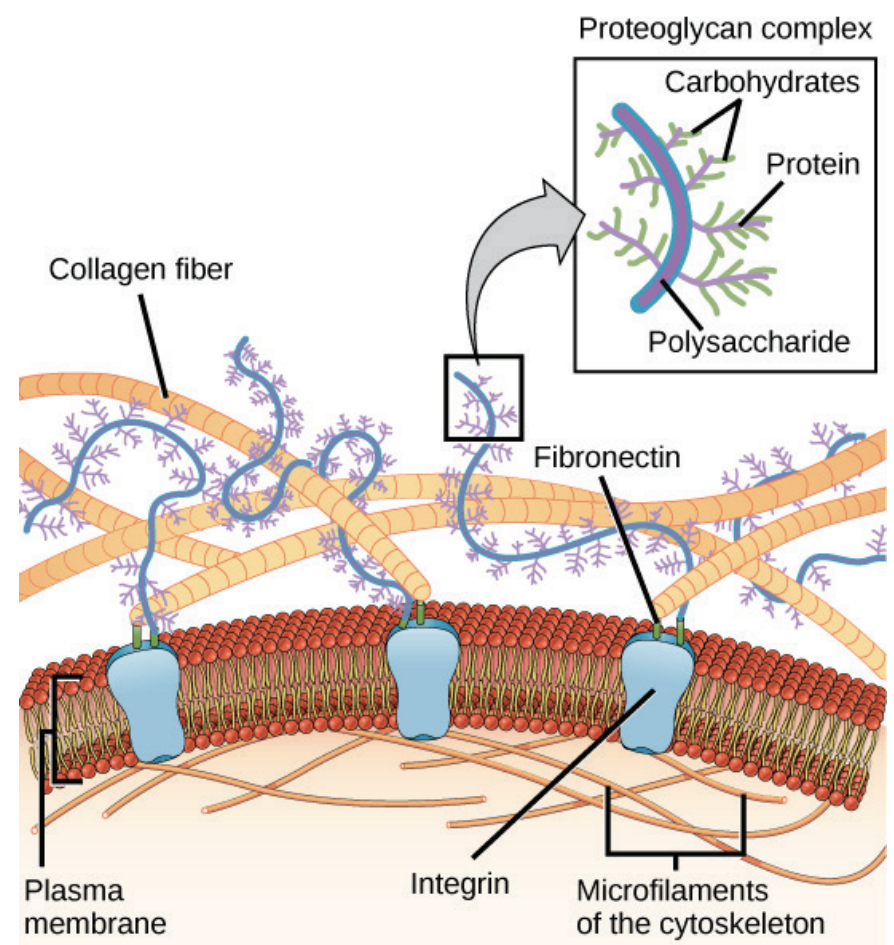

Figure 2. Schematic representation of the ECM structure in contact with a cellular membrane (open source) [21]

\subsection{NATURAL ECM-DERIVED COMPONENTS USED IN TE APPLICATIONS}

The main ECM components used in the development of biomaterials are: collagen, laminin, fibronectin, elastin, keratin, hyaluronic acid, chitosan and GAGs. In what follows, a brief description will be given on the natural components that are mostly used in the fabrication of electrospun scaffolds or in the plasma biofunctionalization of electrospun fibers.

\subsubsection{Collagen}

Collagen is the major polymeric component of the ECM. It is constituted of polypeptide chains displaying triamino acid sequences of glycine-A-B where A and $B$ are mostly hydroxyproline or proline but can be any of a series of amino acids. These polypeptides are organized into micro-fibrillary triple helices that arrange together following different architectures to form collagen fibers. More than 28 different collagen types have been identified up to date from which types I, II, III and IV are the most studied with an excessive use of 
collagen type I in TE applications [8]. Collagen generally binds to glycoproteins, growth factors and structural proteins such as laminin and elastin to afford specific tissue characteristics and it was shown that each of the collagen types plays a role in the constructive remodeling of tissues [22]. The use of collagen in TE applications is mainly due to its biocompatibility, great ability to enhance cell adhesion and proliferation, mechanical properties and enzymatic degradation by metalloproteinases and collagenases $[23,24]$. Many authors have electrospun collagen nanofibers for their use in wound dressings, blood vessel, cartilage, tendon and other TE applications. Collagen is a thrombogenic component since it activates the conversion of fibrogen into fibrin known by its capacity to capture activated platelets to generate a clot [8]. The commercial collagen type I is generally obtained from bovine dermis, human placenta or rat tail. Although extensively researched, many drawbacks are associated with use of collagen in biomedical applications. In addition to the high cost of purification and high risk of disease transmission, collagen possesses some antigens in its central helix that were shown to cause immunological responses in vivo $[8,25]$.

\subsubsection{Gelatin}

Gelatin is a derivative of collagen obtained by a physico-chemical degradation and denaturation of its triple-helix structure. The production process highly affects the gelatin properties. It is composed of 19 amino acids and is organized in single-stranded structure. It possesses comparable hemostatic characteristics to collagen and is degraded enzymatically by collagenases [25]. A major advantage of gelatin is its possession of a great non-antigenicity, thus it is less immunogenic than its precursor. Gelatin-based scaffolds were commonly used in TE applications due to their good biocompatibility and their ability to promote cell adhesion, proliferation, differentiation and migration [26]. However, unlike other polymers, gelatin is a polyelectrolyte polymer possessing quite a number of anionic and cationic groups associated with a strong ability of hydrogen bonding. As a consequence, a 3D macromolecular network can be formed, tremendously decreasing the mobility of gelatin chains thus making the development of fibers a challenge [27]. Despite the poor electrospinnability of gelatin, some authors succeeded to electrospun gelatin fibers but the solvents used to obtain relatively good fibers were rather toxic such as trifluoroethanol and hexafluoropropanol [28]. Therefore, gelatin has been broadly coated on electrospun nanofibers made up of other polymers.

\subsubsection{Laminin}

Laminin is a complex protein found in the ECM particularly within the basal lamina and that can independently self-assemble into networks or associate with other ECM components such as collagen IV. Three polypeptide chains $(\alpha$, $\beta$ and $\gamma$ ) intersected into the form of a cross-like structure are found to compose this protein. There are several variants of this heterotrimeric protein 
that depend on the particular composition of each polypeptide chain [22]. Laminin has been reported to be among the first and most critical ECM components to play a role in enhancing and supporting adhesion, growth, differentiation and migration of several cell types in particular neuronal cells. It contains the amino acid sequence isoleucine-lysine-valine-alanine-valine that enhances and controls neurite outgrowth. Therefore laminin was extensively used in neural TE [29,30]. Neal et al. demonstrated that electrospun laminin fibers promoted a higher degree of cell attachment and neurite extension from adipose derived stem cells than laminin films [31]. However, the electrospinning of laminin have been mainly hindered by the instability of the resulting fibers, but coating or conjugating electrospun fiber surface with laminin has been extensively performed and showed promising results in tissue regeneration [32].

At first, tissue engineers considered natural polymers as promising materials for the fabrication of scaffolds because of their attractive bioactivity. However, many studies rapidly revealed that most of the natural materials are associated with several drawbacks:

- Weak mechanical stability [33]

- Difficulty of obtaining large amounts of materials and high processing cost [34]

- Restricted designing possibilities without alteration of the biological properties [35]

- Weak resistance of enzymatic degradation; uncontrolled degradation rate since enzymatic activity differs between hosts [36]

- Intense immunogenic reactions [37]

- Risk of disease transmission from allogenic or xenogenic materials [38]

Therefore, synthetic biodegradable polymers overcoming all these limitations were developed and were extensively used as basic materials for the fabrication of scaffolds. The major downside of synthetic biomaterials is their hydrophobicity and the lack of biochemical recognition sites necessary for different cellular processes. Nowadays several advances in surface tissue engineering come to solve this issue.

\subsection{SYNTHETIC BIODEGRADABLE POLYMERS USED IN TE APPLICATIONS}

Since an ideal polymer does not exist because of the wide-ranging TE applications, researchers have developed numerous synthetic polymers. A library of materials was used to synthetize polymers and then to engineer scaffolds that match to the best the specifications of a particular application. Among the synthetized biodegradable polymers, the aliphatic polyester family 
is nowadays the most appealing group meeting various medical and physical requirements for safe clinical applications. The biocompatibility and biological inertia of polyesters were confirmed after their use in several biomedical applications [8,39]. Moreover, their synthesis via condensation polymerization or ring-opening is relatively easy which increases their commercial availability. Although numerous polyesters are nowadays available, their hydrolytically steady ester bond limits their degradability and makes only the ones with relatively short aliphatic chains appropriate for tissue-engineered scaffolds [8,40]. Poly(glycolic acid) (PGA), poly(lactic acid) (PLA), poly(lacticco-glycolic acid) (PLGA), polycaprolactone (PCL), poly(butylene succinate) (PBS) and poly(hydroxyalkanoate) (PHA) are the ones that are currently adopted in the majority of biomedical applications [35,41]. In addition to their versatility regarding chemical and physical properties, a custom-tailored degradation rate can be obtained. Therefore, a plethora of papers have focused on the fabrication of nanofibers using these synthetic polymers, but PCL is by far the most extensively considered in the wide literature of electrospinning, followed by PLGA, PLA and PGA (Figure 3). Therefore, in what follows, we will be restricted to a brief overview on these aliphatic polyesters.

\subsubsection{Poly(glycolic acid) (PGA)}

PGA also known as polyglycolide is one of the first biodegradable polymers ever explored in biomedical applications. PGA is characterized by an elevated melting temperature exceeding $200{ }^{\circ} \mathrm{C}$, a high crystallinity (44-55\%) and an excellent tensile strength (12.5 GPa) [42]. These characteristics, together with PGA's great biodegradability, have attracted the medical community to use it in the fabrication of resorbable sutures that were commercialized under the name of DEXON ${ }^{\circledR}$ and have been extensively used since 1970 . With the rise of TE applications, the physico-chemical properties of PGA accompanied with its acceptable bioresponsive properties such as good cellular viability, have also appealed tissue engineers to fabricate PGA scaffolds for tissue regeneration $[8,37]$. When implanted in the body, PGA degrades into the non-toxic glycolic acid that can be excreted via the urinary system or via the respiratory system after being converted into $\mathrm{CO}_{2}$ and $\mathrm{H}_{2} \mathrm{O}$ [42]. PGA scaffolds were therefore fabricated and were used in several TE applications such as bone, tendon, cartilage, intestinal, and neural regeneration [8]. Nevertheless, several studies have rapidly demonstrated that the use of PGA in TE involves several drawbacks. First, the rapid degradation of PGA leads to a reduced mechanical strength of the scaffold within 1-2 months with a total loss of its mass within 6-12 months [43]. Therefore, this degradation rate does not coincide with the regeneration rate of most of the tissues. In particular, when it comes to nanofibers, the degradation is even faster compared to macroscale scaffolds. The higher area-to-volume ratio and enhanced porosity facilitate the penetration of water into the highly crystalline PGA nanomatrix which 
increases its degradation rate [36]. Dong et al. showed that PGA nanofibers degraded only within 20 days and barely supported the growth of porcine smooth muscle cells in the first few days [44]. This is one of the reasons explaining why the electrospinning of PGA is less considered compared to the other polyesters. Moreover, the fast degradation of PGA causes a rapid production of glycolic acid leading to its local accumulation at high levels which is associated, despite its aforementioned non-toxicity, with undesired strong inflammatory responses $[45,46]$. Furthermore, PGA exhibits a limited solubility in the most common solvents, it is rather soluble in toxic highly fluorinated solvents such as hexafluoro-2-propanol, which also reduces the electrospinning of PGA fibers [41]. Recognizing the above, most of the recent applications have coupled PGA with other biodegradable polymers in the development of electrospun scaffolds.

\subsubsection{Poly(lactic acid) (PLA)}

Lactic acid is a natural metabolic by-product generated in the muscles by anaerobic glycolysis and can be degraded into $\mathrm{CO}_{2}$ and $\mathrm{H}_{2} \mathrm{O}$ which are further eliminated from the body via the respiratory system. It is a chiral molecule that constitutes the monomer building unit of PLA or polylactide. It can be produced by converting a starch having a vegetable origin or a sugar via a petrochemical process or a bacterial fermentation [42,47]. Because of its chirality, PLA can be synthetized in four different forms: poly(D-lactic acid) (PDLA), poly(L-lactic acid) (PLLA), poly(D,L-lactic acid) (PDLLA) and mesopoly(lactic acid). PLLA and PDLLA have been widely studied and have shown promises in the biomedical and TE fields [8]. PLLA has a relatively high melting temperature of around $175^{\circ} \mathrm{C}$ and a tensile strength of $4.8 \mathrm{GPa}$ [48]. The extra methyl group in PLA renders it more stable and more hydrophobic than PGA. Therefore, it exhibits a slow degradation compared to PGA. When hydrolyzed, PLLA loses its strength within approximately 6 months, but preserves its mass for long periods of time and it can take up to several years to totally degrade [41]. After commercializing an internal bone pin made up of PGA under the name of Biofix ${ }^{\circledR}$ in 1984, the base material was converted to PLLA starting from 1996 since it demonstrated a much better stability at long-term. PLLA has also been used in the fabrication of surgical sutures [8]. Moreover, it attracted a strong interest for the use in tissue regeneration because of its proper mechanical characteristics and degradation rate matching the properties and the healing time of a number of tissues. Furthermore, tissue engineers can take advantage of its piezoelectric characteristics $\left(d_{25}=10 \mathrm{pC} \mathrm{N}^{-1}\right)$ by stimulating the tissue via an electro-mechanical transduction thus activating the scaffolds not to just serve as passive structural support for cells [49,50]. Nerve, bone, blood vessel, tendon, cartilage, liver and other TE fields have experienced a successful use of PLLA scaffolds [8]. Particularly, in the past decade electrospun PLLA scaffolds are being increasingly utilized. This is partially due to the fact that PLLA is soluble in the majority of organic solvents such as 
chlorinated solvents, tetrahydrofuran (THF), dioxane and acetonitrile; and by choosing appropriate solvent systems, a very good quality of PLLA fibers can be obtained [51,52].

The amorphous nature of PDLLA is due to the arbitrary positioning of its 2 isomeric monomers. This results in a significantly reduced mechanical strength $(1.9 \mathrm{GPa})$ compared to PLLA [42]. PDLLA further loses its strength when hydrolyzed after 1-2 months and its mass within almost a year. Therefore, PDLLA has been used in drug delivery systems or in the rare TE applications requiring low strength scaffolds [43]. As a consequence, PDLLA nanofibers were rarely electrospun for TE purposes, unless the polymer is blended with other biodegradable polymers [53-55].

\subsubsection{Poly(lactic-co-glycolic acid) (PLGA)}

The slow degradation time of PLLA is a limiting factor in some TE applications that involve relatively fast-regenerating tissues. Therefore, tissue engineers randomly copolymerize PLLA or PDLLA and PGA to obtain PLGA also known as poly(lactic-co-glycolide), thus combining the properties of the two polymers. The high commercial availability of PLGA, together with its easy processability in almost all sizes and shapes makes it one of the most investigated synthetic polymer in TE but also in other biomedical applications such as drug delivery systems and sutures $[37,43]$. Depending on the intended TE application, the copolymer composition should be delicately selected, since PLGA degradation is strongly influenced by the lactic acid/glycolic acid ratio. A composition of lactic acid between 25 and $75 \%$ leads to the formation of PLGA having an amorphous nature that is much more hydrolytically unstable than the homopolymers. For instance, a 50/50 PLGA degrades within 1-2 months, a 75/25 PLGA degrades within 4-5 months and a 85/15 PLGA degrades within 5-6 months [48]. PLGA has demonstrated great cell-responsive properties (adhesion and proliferation) in different TE fields such as bone, nerve, cartilage, tendon, liver and skin. For these applications, PLGA scaffolds were developed making use of various techniques such as porogen leaching, gas foaming, microsphere sintering and electrospinning [8,56]. In particular, fibrous PLGA scaffolds with controlled diameter and porosity are reported to be easily produced by electrospinning [57]. Several solvents can be used for the electrospinning process since PLGA is soluble in a broad range of common solvents including tetrahydofuran, chlorinated solvents, acetone and ethyl acetate [58]. In opposition to PGA, PLGA (50/50) nanofibers $(550 \mathrm{~nm})$ have shown a slower degradation compared to PLGA films $(0.5 \mathrm{~mm})$ because of the reduced bulk autocatalysis effect resulting from the accumulation of the degraded acidic products [59]. The porosity of the nanofibrous matrices is the leading cause of this reduction in the autocatalysis effect $[60,61]$. 


\subsubsection{Polycaprolactone (PCL)}

In 1930, PCL was synthetized by the Carothers group to be one of the first developed synthetic polymers. It is obtained via a ring-opening polymerization of the relatively cheap monomer building block $\varepsilon$-caprolactone by using cationic and anionic catalysts [62]. It is a semi-crystalline polymer having a crystallinity that tends to decrease with increasing the molecular weight and a melting temperature between 55 and $60^{\circ} \mathrm{C}$ [8,63]. In the 1970s and 1980s, PCL has attracted some attention together with other synthetic biodegradable polyesters for its use in biomedical applications, especially in the developing of drug-delivery devices. However it was rapidly overwhelmed by the polyglycolides and the polylactides because of its very prolonged degradation time that can reach up to 3-4 years. Two decades later, a massive resurgence of PCL has coincided with the rise of the TE field due to its several advantages over other biodegradable polymers [62]. Despite its relatively low tensile strength (23 MPa), PCL possesses great rheological and viscoelastic properties such as a very high elongation at break (4700\%), which makes the development of a broad range of PCL scaffolds having various sizes and shapes relatively very easy [8]. Therefore, numerous techniques were involved in the manufacturing of PCL scaffolds such as: porogen leaching, phase-separation methods, liquid-liquid phase separation, supercritical fluid methods, solid-free form fabrication, stereolithography, 3D printing, fused deposition modeling and electrospinning [62]. In particular, PCL electrospinning has known a steep continuous rise starting from 2003. PCL is soluble in wide-ranging solvents such as tetrahydrofuran, dimetylformamide, acetic acid, formic acid, methylene chloride, pyridine, dichloroethane, methylene chloride, chloroform and other chlorinated solvents [64]. Previous studies have revealed that PCL fibers are absolutely non-toxic since they do not generate acidic degradation products, which is an issue to be considered sometimes in the degradation of PLGA and PLA because of possible inflammatory responses $[65,66]$. PCL has been blended or co-polymerized with other polymers in order to increase the degradation rate. Nevertheless, PCL nanofibers, like PGA, have been reported to degrade faster than PCL macroscale scaffolds [36]. Interestingly, PCL fibers and other scaffolds were revealed as promising candidates in bone, nerve, cartilage, tendon, ligament, skin, blood vessel and other tissue regeneration processes $[62,63,67]$. 
$\square \mathrm{PGA} \square \mathrm{PDLLA} \square \mathrm{PLLA} \backsim \mathrm{PLGA} \square \mathrm{PCL}$

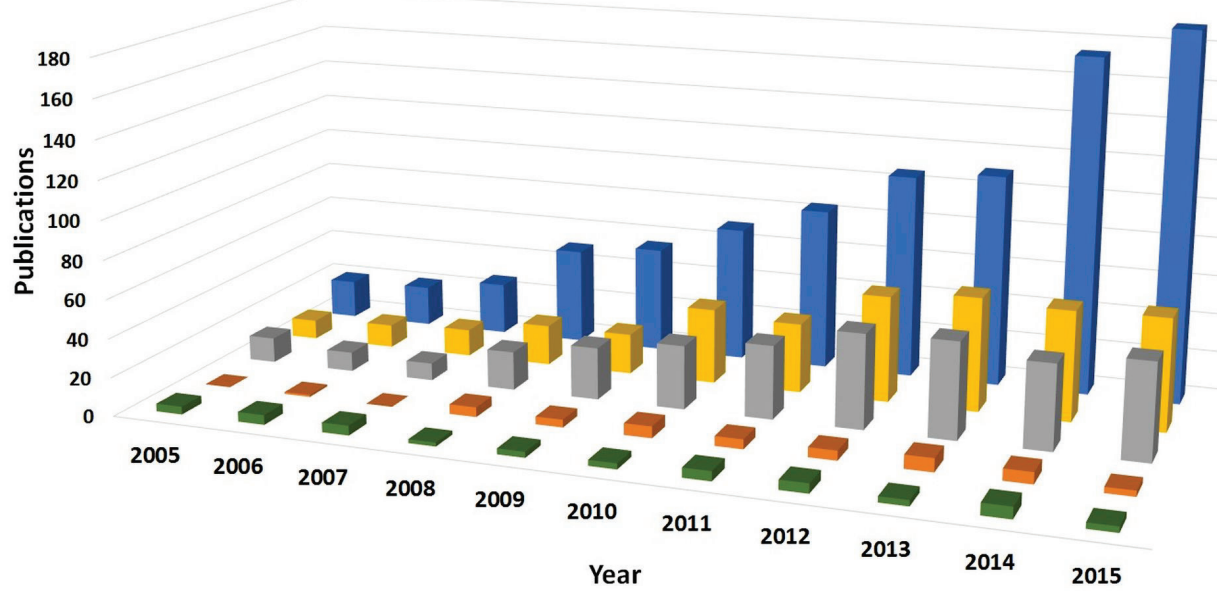

Figure 3. Publications using electrospun biodegradable polyesters during the last decade. Sourced from Web of Science.

\subsection{ELECTROSPINNING}

After a great deal of efforts, several chemical, physical, electrostatic and thermal techniques were developed to fabricate scaffolds mimicking the fibrillary structure of the ECM, such as template synthesis, liquid-liquid phase separation, vapor-phase polymerization, self-assembly and electrospinning [68-71]. This last technique, also called electrostatic spinning has been first introduced in the 1930s, but it was until the end of the $20^{\text {th }}$ century that it received a great surge of interest within the scientific community, after Reneker et al. discovered the possibility of generating electrospun fibers from various polymers [72,73]. The massively increasing literature on electrospinning has paved the path towards great achievements in the TE field. It is preferred over the other techniques due to its versatility, simplicity and low cost. Moreover, an attractive strength of electrospinning is its capacity to easily adjust the fiber diameter down to the nanometer scale thus not only recapitulating the structure of the ECM but also its size. Electrospun nanofibers display a higher surface-to-volume ratio compared to microfibers, thus providing much more binding sites for proteins which leads to a good cellular adhesion that is essential for other cellular activities [7,36,74,75]. Binulal et al. showed that human mesenchymal stem cells (HMSCs) adhere, spread and proliferate more efficiently and rapidly on PCL nanofibers compared to PCL microfibers. Furthermore a successful differentiation of HMSCs into osteoblastic lineage and subsequent mineralization were observed on PCL 
nanofibers [76]. Wang et al. cultured human embryonic stem cells on fibers made up of Tussah silk fibroin and having diameters of 400 and $800 \mathrm{~nm}$ and showed increased cellular viability on the $400 \mathrm{~nm}$ fibers [77]. In a study conducted by Yang et al., the rate of neural stem cells differentiation was shown higher on PLLA nanofibers than on microfibers [78]. Another key feature of electrospinning is its capacity to tailor the nanofiber mesh porosity providing a large number of intra/inter connected pores allowing the cellular migration and the essential supply of nutrients for the cells $[75,79]$. Electrospinning can be also employed to design the nanofibers into specific arrays or 3D hierarchical architectures (e.g. hollow tubes, stacked arrays). Moreoever, several fiber morphologies can be obtained such as porous, ribbon, beaded and core-shell fibers [80].

\subsubsection{Concept and mechanism of electrospinning}

A combination of the two concepts namely electro-spraying and spinning is involved in the electrospinning process. The basic set-up is mainly composed of five major parts: a syringe containing the polymer solution, a syringe pump, a power supply, a metallic tip or needle and a metallic collector that can have various morphologies (e.g. plate, cylinder). A schematic representation of the set-up is shown in Figure 4. The flow rate of the solution is regulated by the pump in order to carry the solution via tubes or capillaries from the syringe to the metallic tip. When a droplet of the solution comes out of the tip, a high electric field is applied between the tip and the collector which both serve as electrodes. This causes an instability within the solution resulting from the induction of electric charges on the droplet, thus forcing the ions of the solution to aggregate at the surface of the droplet. Simultaneously, the spherical droplet deforms adopting a conical shape named "Taylor cone" and undergoes two main types of electrostatic forces: a reciprocal repulsion of the surface charges and a Coulombic force expended by the external electric field generated between the tip and the collector. When increasing the voltage above a critical threshold, the electrostatic forces oppose and overcome the surface tension of the polymer solution and a charged jet is erupted from the Taylor cone and accelerated towards the metallic collector. During the travelling of the jet through the air between the tip and the collector, it experiences spreading and elongation processes accompanied with the evaporation of the solvent. Therefore, thin solid polymeric fibers are deposited on the collector in the form of non-woven mat $[35,36,80]$. 


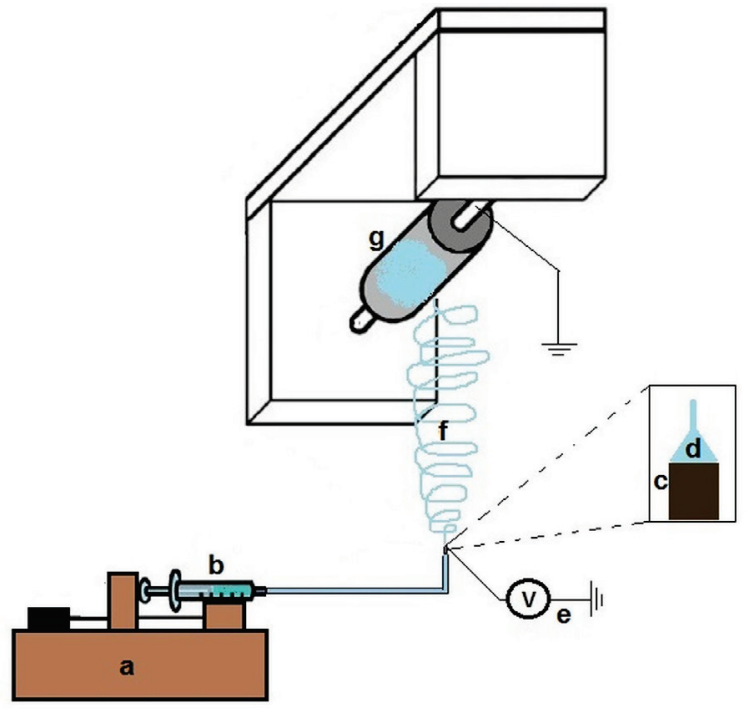

Figure 4. Schematic representation of the electrospinning set-up (a: syringe pump, b: syringe containing the polymer solution, c: metallic tip, d: Taylor cone, e: high voltage power supply, f: polymer jet, g: collector)

\subsubsection{Electrospinning parameters}

Despite the theoretic simplicity of the electrospinning process, some challenges are to be faced in order to obtain a good quality of fibers. The spinnability as well as the fiber diameter, morphology, uniformity and alignment are mainly influenced by 2 types of parameters: substrate-related parameters and process-related parameters. The fiber defects such as the formation of beads, junctions and pores are controlled by optimizing these parameters. Recently, environmental factors such as temperature and relative humidity were shown to have minor effects on the fiber size and morphology. Complete reviews and book chapters have discussed in detail the influence of the electrospinning parameters on the fibers [75,81]. In what follows, the most important parameters will be cited and very briefly discussed.

\subsubsection{Substrate-related parameters}

The main substrate-related parameters include the polymer concentration, molecular weight, viscosity and surface tension. The polymer concentration and molar mass affect the solution viscosity, widely known to have an influence on the uniaxial stretching of the electrically charged jet $[7,36]$. For example, a low concentration or molar mass result in a low viscosity limiting the erupted jet from withstanding the electrical forces. Therefore, the polymer chains are broken up into fragments and beads are generated. Increasing the concentration or the molar mass gives rise to more entanglements among the 
polymer chains thus forming a mixture of fibers and beads. A further increase in the polymer concentration finally results in optimized solution viscosities and subsequent formation of smooth beadless fibers [81]. Increasing the concentration is reported in many studies to generate uniform fibers with larger diameters (Figure 5) $[73,82,83]$. However, when the concentration exceeds a critical value, a very high viscosity is obtained thus hindering the flow of the polymer solution that frequently dries and obstructs the tip [36].

The literature concerning the influence of the solution surface tension on the fiber size and morphology is controversial. While some authors have reported that reducing the surface tension is beneficial and results in bead-free fibers, others showed that it is not always the case. It is clear that it mainly depends on the polymer and the system of solvents used $[36,81]$.
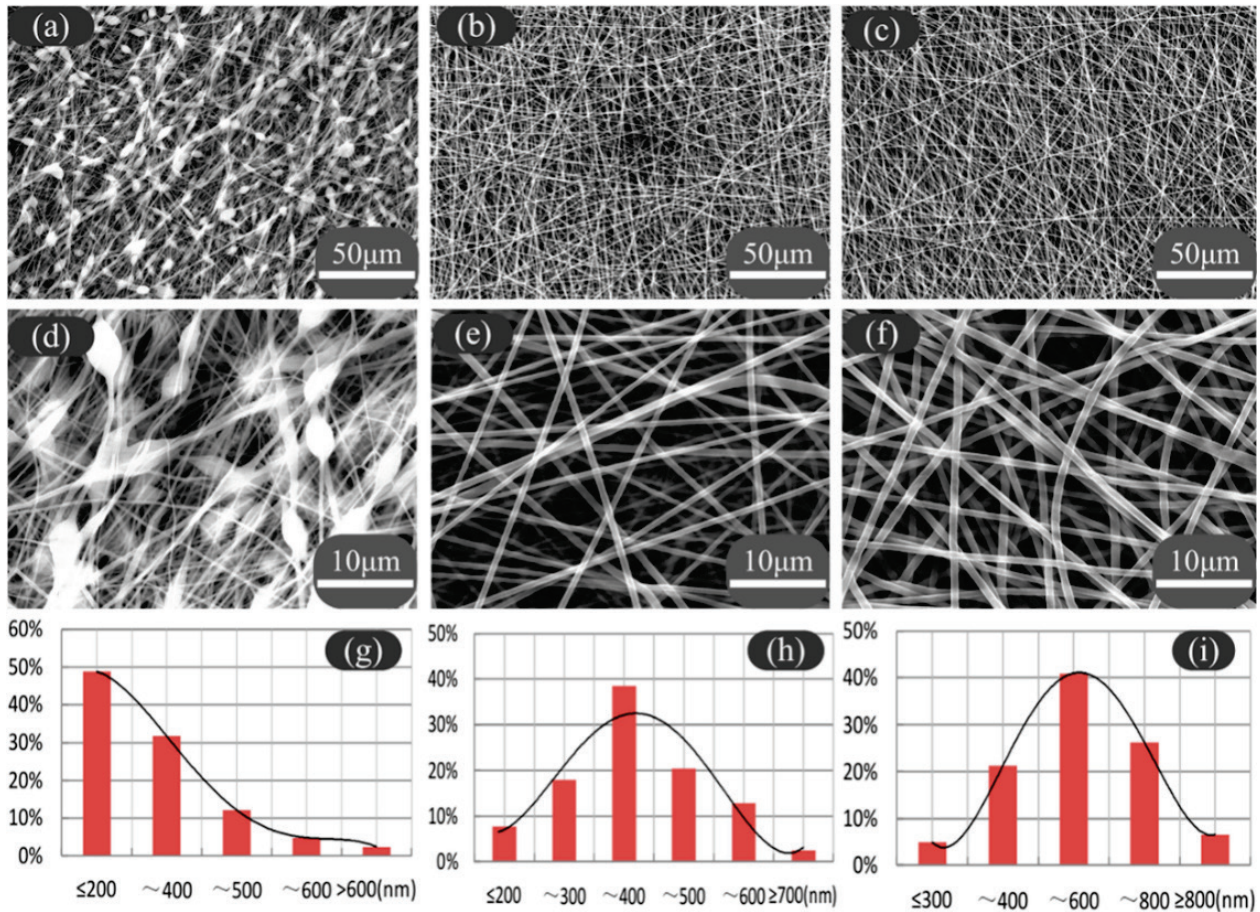

Figure 5. PLGA nanofibers electrospun from solution (PLGA-

tetrahydrofuran/dimethylformamide) having a concentration of $0.2 \mathrm{~g} \mathrm{~mL}^{-1}(\mathrm{a}, \mathrm{d}, \mathrm{g})$, $0.3 \mathrm{~g} \mathrm{~mL}^{-1}(\mathrm{~b}, \mathrm{c}, \mathrm{h})$ and $0.4 \mathrm{~g} \mathrm{~mL}^{-1}$ (c, f, i). Reprinted from [82]. Copyright ${ }^{\odot} 2015$ with permission from American Chemical Society. 


\subsubsection{Process-related parameters}

The most important process-related parameters are the applied electric field, the polymer flow rate and the distance between the tip and the collector. A crucial step in the electrospinning process is optimizing the applied voltage in order to obtain a continuously steady Taylor cone over time with the same amount of polymer ejected towards the collector per time unit [64]. Some studies have reported that increasing the applied voltage reduces the fiber diameter because it can increase the electrostatic repulsion forces on the jet leading to an additional stretching of the polymer solution [36,81]. For instance, Katti et al. found that an increase in the applied voltage from 0.375 to $1.000 \mathrm{kV} \mathrm{cm}^{-1}$ significantly reduced the diameter of PLGA fibers, but above this voltage the fiber diameter was no more considerably changed [84]. In contrast, other studies have demonstrated that higher voltages gave rise to larger fiber diameters. In addition to those observations, many groups stated that a high voltage is accompanied with a great probability of bead formation $[7,81]$. Therefore there is an optimal range of applied voltage for each particular polymer-solvent system.

Most of the studies agreed that low feeding rates of the polymer solution within the syringe are preferable over high flow rates. On one hand, when the flow rate is low, the polymer solution will have time to polarize. On the other hand, high flow rates lead to the formation of bead fibers with large diameters largely owing to the insufficient solvent evaporation before the jet reaches the collector $[7,81,85]$.

The solvent evaporation also depends on the distance between the tip and the collector. This distance affects as well the whipping processes, thus it should be optimized in order to generate uniform and smooth nanofibers. Defective fibers with large diameters are generally observed when this distance is small, whereas as the distance increases, the fiber diameter normally decreases $[7,75]$.

The deposition of the fibers on the collector can be affected by the collector's shape. A number of metallic collectors have been developed in order to generate aligned fibers. Three different types of forces are involved in order to obtain aligned fibers: a rotating mandrel exerts mechanical forces, parallel permanent magnets exert magnetic forces and parallel electrodes exert electrostatic forces. In many TE applications, in addition to the fibrillary structure of the scaffold, the anisotropy in the topography was demonstrated to have a positive effect on the mechanical properties and the cellular behavior $[71,86]$. 


\subsection{DIFFERENT FUNCTIONALIZATION APPROACHES OF ELECTROSPUN BIODEGRADABLE POLYMERS}

Once the mimicry of the ECM structure addressed by creating nanofibers, a bio-functionalization needs to be tackled since cells do not only recognize topographical cues but also biochemical cues that significantly affect their behavior. Surfaces play a pivotal role in TE since the majority of biological processes are initiated at the interface between cells and material $[87,88]$. Therefore modifying the surface chemical properties of electrospun nanofibers can strongly and positively impact the cellular behavior. The choice of an appropriate surface modification not compromising the delicate structure of nanofibers is a challenging step. Ion-beam, X-ray, ozone oxidation and gamma radiation are able to introduce reactive chemical functionalities on polymer surfaces, however they often alter the mechanical stability and degrade the polymer, thus rapidly damaging nanofibers [16,74,89-91]. A traditional method used to incorporate and enhance the density of functional groups on biomaterial surfaces is wet chemical treatment. For example, the incorporation of $\mathrm{COOH}$ can arise when applying a surface hydrolysis with $\mathrm{NaOH}$ solution. $\mathrm{NH}_{2}$ groups are added to the surface by aminolysis in which a chemical reaction involves the splitting of a molecule into 2 parts when reacting with a molecule of $\mathrm{NH}_{3}$ [92-94]. Despite the enhanced surface wettability obtained after the incorporation of such groups, many drawbacks associated with wet chemical treatments set some question marks concerning their utilization. First, such treatments are very harsh leading in some cases to a decrease in the mechanical performance and an increase in the rate of degradation thus it can particularly destroy fine structures such as nanofibers [95]. Secondly, many studies have shown that these surface modifications can cause irregular and unwanted etching strongly modifying the surface thus they are not appropriate for nanosized fibers [96,97]. Furthermore, these techniques are not ecofriendly since they demand large amounts of liquids and produce hazardous chemical waste [43]. To avoid these surface modifications, some researchers have blended natural polymers and other bioactive molecules with the synthetic polymer solution prior to the electrospinning thus specifically functionalizing the nanofibers for particular TE applications. Collagen, laminin, gelatin, elastin and chitosan have extensively been blended with synthetic polymers to produce nanofibers serving as scaffolds for nerve, blood vessels, skin and bone regeneration together with other TE applications [98-103]. Carbon phosphates, serving as bone grafting replacements to fill bone empty spaces and damaged areas, have been blended with polymer solutions to fabricate nanofibers having potentials in osteoconductivity, osteoinductivity and osteointegration [104-106]. Short peptide sequences of specific ECM proteins constituting bioactive ligands for particular cellular receptors have been added to electrospinning solutions [107]. Table 1 shows some of the blending solutions that have been prepared so far to fabricate nanofibers used in different TE applications. Although this method showed enhanced cell- 
material interactions, several disadvantages cannot be ignored. Embedding bioactive molecules inside the nanofibers can cause the masking of their bioactivity [104]. The harsh conditions of the electrospinning might modify the bioactive sequences of the some peptide-based functionalities and proteins [108]. Moreover, because of the limited solubility of natural polymers in water, highly acidic and toxic solvents such as trifluoroacetic acid and 1,1,1,3,3,3hexafluoro-2-propanol (HFP) are being used for electrospinning. In addition to their undesired toxicity, these solvents can compromise the biological activity of the added molecules [109]. For example, Zeugolis etal. revealed that the beneficial properties of collagen are lost when it is dissolved in 2,2,2trifluoroethanol or HFP and electrospun. These solvents caused a collagen denaturation thus altering the specific biological sites recognized by the cellular receptors [110]. Yangetal. also showed that collagen type I electrospun fibers were denaturated when using HFP [111]. Furthermore, the presence of natural bioactive materials inside the nanofibers can weaken the electrospun fibrous network. An important downside of adding bioactive materials in the electrospinning solution, is the difficulty of controlling the process parameters to obtain good nanofibers [26].

As an alternative to the abovementioned functionalization methods, plasmabased surface modification is gaining a great interest in the TE field. It is a simple, versatile and suitable method to incorporate functional groups on polymer surfaces without the use of solvents. A highly controlled treatment can be performed by adjusting all the process parameters to specifically modify polymer surfaces while avoiding the damaging of the scaffolds $[15,112,113]$. Therefore plasma is very adequate to treat delicate structures such as nanofibers. Moreover, the action of plasma treatments is limited in depth to few nanometers below the surface thus not affecting the bulk properties of the base material that conserves its mechanical stability $[41,74,114]$. Plasma treatment has the potential to homogenously modify the surface of complex shaped biomaterials which makes it even more attractive for the functionalization of nanofibers $[115,116]$. In addition to its capacity to incorporate functional groups onto polymer surfaces, plasma treatment is also performed to deposit polymer coatings. These can be followed by the immobilization of proteins or other bioactive molecules on the scaffolds [117121]. Plasma biofunctionalization can overcome the downsides of blending biomolecules with the polymer solution prior to the electrospinning as well as the limitations of the direct coating of such molecules on the nanofibers. In the latter, a stable deposition is difficult to attain and biomolecules can aggregate in the interfiber spaces masking the pores of the electrospun matrix which hinders cellular in-growth and migration [104]. Furthermore, the concentration of proteins on the scaffold surface was demonstrated to be an important factor in regulating cellular activities. Shi et al. detected a correlation between the concentration of fibronectin and the adhesion of NIH 3T3 cells on nanofibers [122]. By plasma-treating the nanofibers, the density of the 
covalently immobilized biomolecules can be optimized since a highly specific surface chemistry can be obtained. Figure 6 gives a schematic illustration summarizing the surface modification techniques of nanofibers. Acknowledging these numerous advantages, the following section will give a more general description of different plasma surface functionalization approaches, accompanied with an overview on how these approaches have improved the performance of different types of polymeric biodegradable nanofibers in several TE fields.

Table 1. Synthetic polymer/biomolecule solutions used for the electrospinning of nanofibers used in various TE applications.

\begin{tabular}{|c|c|c|c|c|}
\hline $\begin{array}{l}\text { Synthetic } \\
\text { polymer }\end{array}$ & Bioactive agent & Solvent & $\begin{array}{c}\text { Potential } \\
\text { application }\end{array}$ & Ref. \\
\hline PCL & collagen type I & HFP & nerve TE & [123] \\
\hline P(LLA-CL) & fibrinogen & $\begin{array}{l}\text { HFP/Dulbecco's } \\
\text { modified eagle } \\
\text { medium (DMEM) }\end{array}$ & skin TE & [124] \\
\hline PCL & $\begin{array}{c}\text { gelatin } \\
\text { collagen/elastin }\end{array}$ & HFP & cardiovascular TE & [125] \\
\hline PLA & gelatin & $\begin{array}{c}2,2,2- \\
\text {-trifluoroethanol }\end{array}$ & bone TE & [103] \\
\hline P(LLA-CL) & collagen type I & HFP & vascular TE & [99] \\
\hline PLGA & silk fibroin/collagen & HFP & nerve TE & [126] \\
\hline P(LLA-CL) & collagen & HFP & skin TE & [109] \\
\hline PLLA & hydroxyapatite (HA) & $\begin{array}{l}\text { 1,4-dioxane and } \\
\text { dichloromethane }\end{array}$ & bone TE & [106] \\
\hline PCL & chitosan & $\begin{array}{c}\text { trifluoroacetic acid/ } \\
\text { dichloromethane/H } \\
\text { FP }\end{array}$ & nerve TE & [101] \\
\hline PLLA & $\begin{array}{l}\text { granulocytes colony- } \\
\text {-stimulating factor }\end{array}$ & dichloromethane & cardiac TE & [127] \\
\hline PLLA & $\begin{array}{c}\text { HA } \\
\text { HA/collagen }\end{array}$ & HFP & bone TE & [128] \\
\hline PCL & laminin & HFP & nerve TE & [102] \\
\hline P(LLA-CL) & $\begin{array}{c}\text { gelatin } \\
\text { HA/gelatin }\end{array}$ & HFP & bone TE & [105] \\
\hline
\end{tabular}



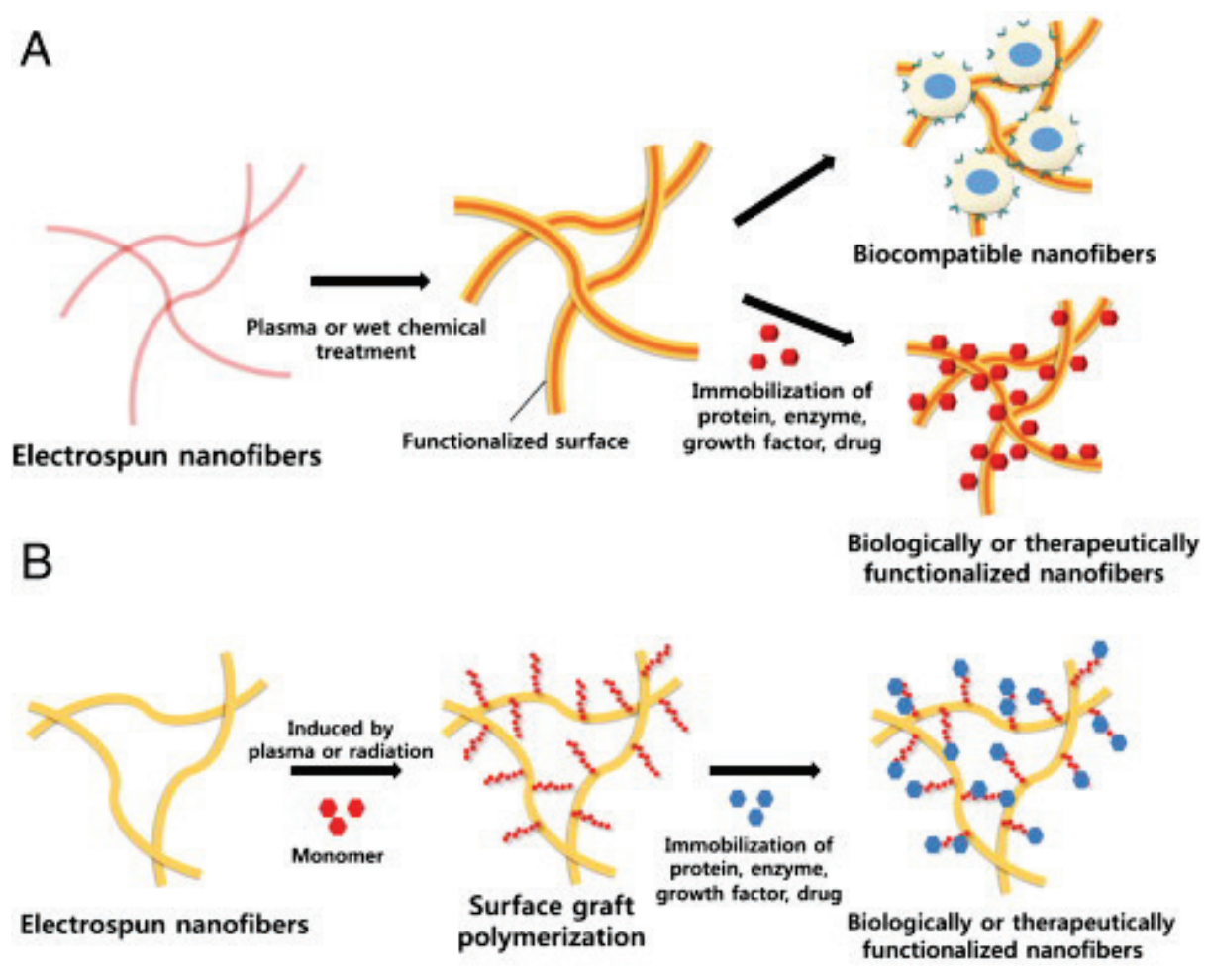

C
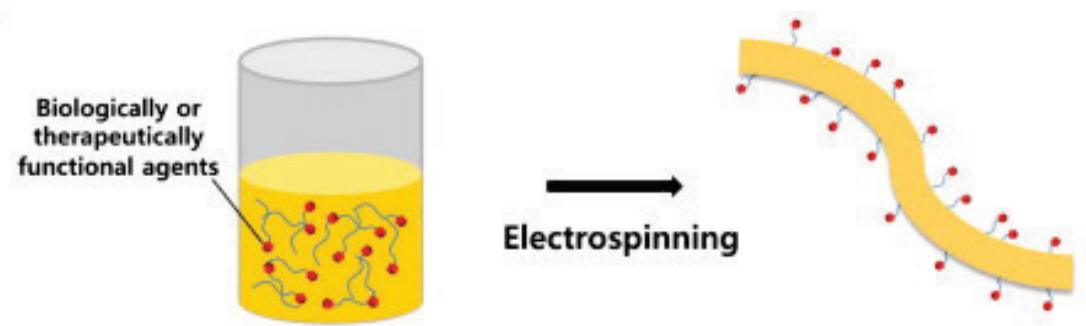

Blend solution

Surface orientation

Figure 6. Surface modification techniques of electrospun nanofibers. (A: Plasma activation or wet chemical treatments, B: Plasma or radiation surface graft polymerization, C: Co-electrospinning) [129].

Copyright ${ }^{\odot} 2009$ with permission from Elsevier. 


\subsection{PLASMA-ASSISTED SURFACE FUNCTIONALIZATION OF NANOFIBERS}

Plasma was designated as the fourth state of matter by Langmuir in 1928 as its properties differ from gases, liquids and solids and a transfer to the plasma state can be obtained by supplying energy to a gas [130]. Plasma is a partially ionized but quasi-neutral gaseous mixture of ions, radicals, free electrons, UV photons and neutral particles such as atoms and molecules [131]. Plasmas are generally classified into 2 categories: equilibrium and non-equilibrium plasmas. Heavy electrons, ions, neutrals and excited species have the same temperature when plasma is in equilibrium. This category is referred to as thermal or hot plasma since the particles have a temperature of $4000 \mathrm{~K}$ or more, thus it cannot be employed to treat heat-sensitive biodegradable polymers. In contrast, in non-equilibrium plasma a thermal inequilibrium is obtained between heavy particles and the electrons when only the electrons are accelerated by applying an electrical field. This gives rise to cold or nonthermal plasma which is used to modify the surface of polymers for TE applications $[41,132,133]$. Several reactors have been built to generate plasma such as corona, radiofrequency (RF) and microwave (MW) discharge reactors. The description of these reactors falls outside the scope of this chapter but is discussed in other chapters and review papers [132,134]. Initially, the scientific community was focusing on low-pressure systems as they display excellent plasma stability giving positive results in term of cellular adhesion, growth and proliferation. An interest in atmospheric pressure systems is progressively growing due to several advantages such as cost efficiency since no vacuum equipment is required and reduced process time. Since the feasibility of electrospinning biodegradable polymers was only demonstrated in the 1990s, researchers were busy in exploring the process and it was until 2004 that plasma treatment of nanofibers began to be studied [36]. Nowadays, the majority of studies involving plasma surface modification of electrospun nanofibers is therefore still limited to low-pressure treatments mainly involving 3 different approaches: plasma activation, polymerization and grafting.

\subsubsection{Plasma activation}

When exposing a polymer to a plasma discharge, the reactive species will induce several plasma-surface reactions enhancing the polymer surface energy. Depending on the choice of the working gas, different functional groups will be added directly or indirectly on the surface. For example, a plasma generated in air, $\mathrm{O}_{2}, \mathrm{~N}_{2}$ or $\mathrm{NH}_{3}$ will incorporate oxygen and/or nitrogen-containing functionalities during the plasma exposure and can create free radicals that could serve after the treatment for the grafting or crosslinking of oxygen groups on surfaces exposed to air. Argon and helium plasma discharges will probably add oxygen-containing functionalities after the 
treatment in the same way $[43,135,136]$. The presence of these polar groups on the polymer surfaces were found to increase the polymer wettability which promotes focal adhesion formation, cellular spreading, growth and several metabolic processes [137]. Changing the plasma process parameters such as treatment time and power can be associated with a change in the hydrophilicity degree of the polymer surface. This degree was shown to be one of the major parameters influencing cellular activities. Webb etal. found that the optimal water contact angle (WCA) for a good adhesion is between 20 and $40^{\circ}$ [138]. However, another study revealed that a high level of cell attachment and proliferation is obtained for a WCA of $55^{\circ}$ [139]. This discrepancy in literature suggests that every cellular type has a particular optimal wettability on a specific type of polymer. Moreover the nature of the grafted groups can have an influence on different cellular behaviors. For example, surface carboxyl and hydroxyl groups were speculated to improve cellular attachment [140]. $\mathrm{NH}_{2}$ groups resulting from $\mathrm{NH}_{3}$ plasma treatment were proven to be more effective in enhancing cellular growth than oxygen containing groups induced by air and $\mathrm{O}_{2}$ plasma treatments $[141,142]$. The type and amount of functional groups incorporated on nanofibers can be more or less custom-tailored by adjusting the plasma conditions. However, because of the highly porous structure of nanofibers, the surface wettability is more difficult to control. Untreated nanofibers display a higher hydrophobicity compared to films made up of the same biodegradable polymer because the pores of the nanofibers increase air entrapment. Moreover, during the electrospinning, chemical groups having lower binding energies can be enriched on the nanofiber surface [143]. After plasma treatment, the incorporation of polar groups on nanofibers causes a sudden increase in the surface wettability since polar liquids will then rapidly penetrate in the porous mats [144]. Many authors experienced an abrupt transfer from superhydrophobic to superhydrophilic nanofibers having a WCA of $0^{\circ}$ after plasma treatment $[12,145,146]$. It is worth mentioning that the plasma activation effect is not permanent over time, a partial hydrophobic recovery occurs by the reorientation of the incorporated groups towards the material bulk and by post-plasma reactions between the modified surfaces and some atmospheric minorities $[147,148]$. Interestingly, our research group has recently discovered that this hydrophobic recovery is less pronounced for PCL nanofibers compared to PCL films. Moreover, no surface modifications of plasma-treated PLLA nanofibers were detected by Dolci etal. at different ageing times after the treatment (Figure 7) [144]. This is presumably due to the fact that the electrospun network is not very exposed to the ambient air since each nanofiber is protected by the neighboring nanofibers. 
A

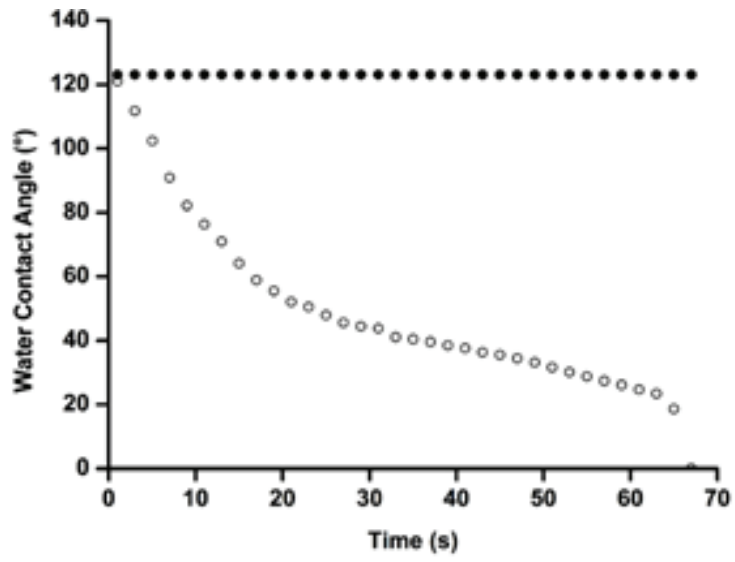

B
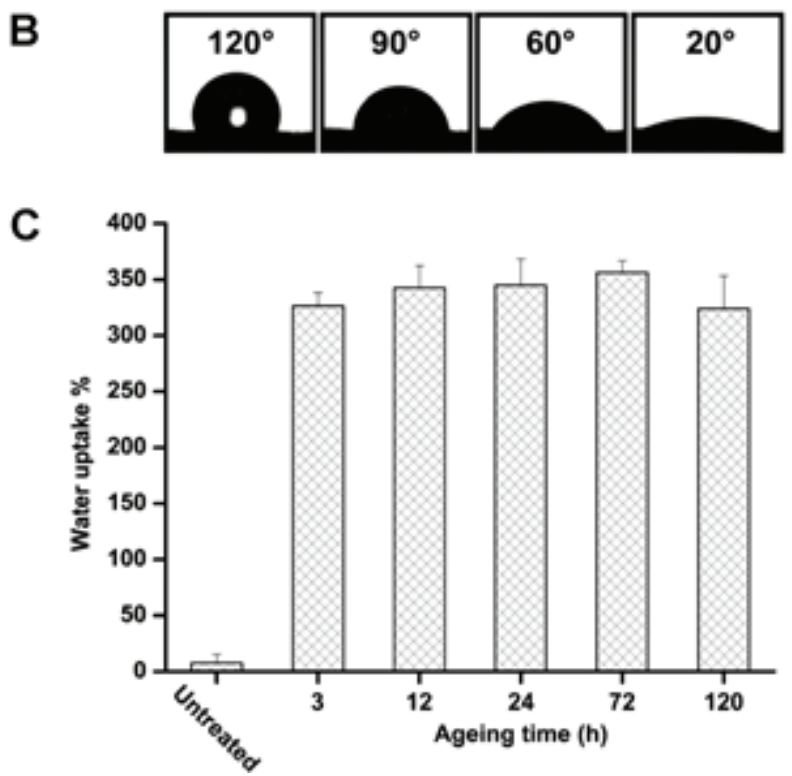

Figure 7. A: Water contact angle behavior of electrospun PLLA fibers soon after air atmospheric plasma treatment (black circles: untreated, White circles: plasma-treated). B: Evolution of the water drop profile. C: Percentage of the water uptake at different ageing times after the treatment [144].

Copyright ${ }^{\odot} 2014$ with permission from Wiley. 


\subsubsection{Plasma-activated nanofibers in TE applications}

\subsubsection{PCL fibers}

As PCL is the most widely electrospun biodegradable polymer, it is the material of choice in the majority of studies involving a plasma surface modification of electrospun fibers. To the best of our knowledge, Fujihara et al. (2004) were one of the first groups to modify electrospun nanofibers making use of plasma technology. Membranes for guided bone regeneration were fabricated by electrospinning a first layer of PCL nanofibers followed by a composite layer of $\mathrm{CaCO}_{3}$ /PCL nanofibers on the surface. The PCL nanofibrous membrane having a high tensile strength served as a mechanical support layer. The second layer was spun after dissolving $\mathrm{CaCO}_{3}$ nanoparticles in the PCL solution to serve as a functional layer since $\mathrm{CaCO}_{3}$ is known to be a good bone filling material enhancing the osteoconductivity. The fabricated membrane was then subjected to an RF plasma treatment operating in air at low pressure. The treatment remarkably modified the nanofiber wettability as the WCA decreased from $139^{\circ}$ to $0^{\circ}$. MTS (3-(4,5-dimethylthiazol-2-yl)-5-(3carboxymethoxyphenyl)-2-(4-sulfophenyl)-2H-tetrazolium) assay and scanning electron microscope (SEM) study revealed good attachment and proliferation of osteoblasts on the treated surfaces thus highlighting the potential of using such membranes in enhancing bone regeneration. No cell tests were performed on untreated nanofibers thus making from the efficiency of plasma treatment a questionable issue [145]. Several studies followed to confirm the plasma efficiency in the development of PCL nanofibers offering promises in bone TE applications. Four years after the research conducted by Fujihara etal., Venugopal etal. spun PCL and PCL/HA nanofibers and also subjected them to an RF air plasma treatment at low pressure. A complete adsorption of water drops was also observed on PCL and PCL/HA nanofiber meshes that were having WCA of around $131^{\circ}$ and $125^{\circ}$ respectively before the treatment. The proliferation of human fetal osteoblasts on plasma-treated scaffolds was significantly higher than on the untreated fibers as shown by MTS assay. Alizarin red staining was performed to detect and quantify calcium mineralization and showed a limited mineralization on PCL fibers compared to PCL/HA fibers with the highest staining intensity on plasma-treated PCL/HA fibers. Therefore the synchronic effect of HA and plasma treatment was shown to be a promising tool for bone regeneration [149]. Proper surface analysis not only limited to WCA measurements but giving precise qualitative and quantitative ideas about the surface chemistry was found essential to deeply understand the mechanisms by which plasma treatment of nanofibers enhances bone regeneration. Therefore, researchers began to chemically characterize PCL surfaces making use of X-ray photoelectron spectroscopy (XPS) and Fourrier transform infrared spectroscopy (FTIR). Yanetal. published two papers on PCL nanofibers exposed to low-pressure RF plasma to study the behavior of mouse osteoblast cells (MC3T3-E1) when cultured on 
such scaffolds. In the first paper random and aligned fibers were subjected to $\mathrm{NH}_{3}+\mathrm{O}_{2}$ plasma whereas in the second paper only random fibers were subjected to plasma generated in 3 different working gas atmospheres: $\mathrm{N}_{2}+\mathrm{H}_{2}$, $\mathrm{NH}_{3}+\mathrm{O}_{2}$ and $\mathrm{Ar}+\mathrm{O}_{2}$. In all cases, the WCA decreased from around $135^{\circ}$ to $0^{\circ}$. Since water rapidly penetrates in the treated nanofibrous matrix, the change of the surface hydrophilicity in function of the plasma treatment time could not be monitored. Therefore, glycerol which is a very viscous polar liquid was used and showed a gradual decrease in the CA with the increase of the plasma exposure times. As a result of the increased wettability, the mechanical properties of the nanofibers such as tensile strength and Young modulus slightly changed after plasma treatment. XPS measurements showed an increase in the surface oxygen that was incorporated in form of $\mathrm{C}-\mathrm{O}$ and $\mathrm{C}=\mathrm{O}$ groups after the treatment. Moreover an incorporation of $\mathrm{N}$-containing functionalities was detected after $\mathrm{N}_{2}+\mathrm{H}_{2}$ and $\mathrm{NH}_{3}+\mathrm{O}_{2}$ plasma treatments. An amine titration test demonstrated that amine groups were only present on the $\mathrm{N}_{2}+\mathrm{H}_{2}$ plasma-treated fibers. These incorporated functional groups enhanced cellular adhesion, proliferation and growth as showed by MTT (3-- 4,5dimethylthiazol-2-yl)-2,5-diphenyltetrazolium bromide) assay and ESEM study. When cultured on the aligned fibers, MC3T3-E1 cells followed the fiber orientation by growing and spreading parallel to the fibers [12,140]. In 2014, Sankar etal. electrospun nano-, micro- and multiscale PCL fibrous scaffolds, subjected them to argon and nitrogen plasma treatment under vacuum and studied their osteoconductivity. A gradual decrease in the WCA was observed when increasing the treatment power with a significant WCA reduction for the nanofiber-containing mats. XPS and FTIR measurements confirmed the surface functionalization of the fibers. Argon plasma treatment incorporated $\mathrm{OH}, \mathrm{C}=\mathrm{O}$ and $\mathrm{C}-\mathrm{O}$ groups on the fiber surface while nitrogen incorporated $\mathrm{OH}$ and $\mathrm{NH}$ groups. An enhanced adhesion, spreading, and proliferation of human mesenchymal stem cells (hMSCs) was detected on plasma-treated fibers with a remarkable adhesion improvement on nanofibers. The differentiation of hMSCs towards osteogenic lineage was evaluated by quantifying the alkaline phosphatase (ALP) activity. An enhanced differentiation was identified on plasma-treated fibers and was further confirmed by the mineralization (alizarin red staining) of the treated scaffolds, revealing the maturation of the differentiated osteoblasts [150]. In a recent study conducted by Jeon etal. plasma technology was used to generate nanosized patterns on electrospun PCL microfibers and to subsequently study the behavior of osteoblast-like-cells (MG63). A modified plasma reactor containing porous $(100 \mathrm{~nm}$ and $800 \mathrm{~nm}$ ) templates and operating in oxygen at low-pressure was fabricated for this purpose. No chemical surface analysis was performed since the goal of this novel plasma technique is mainly to physically alter the surface. SEM analysis showed that increasing the plasma exposure time or power is accompanied with the formation on nanopatterns on the fibers probably due to a plasma etching. As a result a slightly lower Young's modulus was detected. Nanopatterned fibers considerably enhanced cellular attachment and 
proliferation compared to untreated and conventionally plasma-treated fibers, thus making from this new plasma treatment a promising tool for bone and various TE applications [151]. In addition to the bone TE field, plasma-treated PCL fibers were also employed in several other applications such as nerve, cardiac, vascular, skin, hair and ocular TE. Low pressure RF systems were mainly employed to generate plasma in these applications. Sharma etal. were one of the rare groups to use atmospheric pressure plasma to enhance the bioactivity of PCL fibers used to reconstruct ocular surface. Similar surface analysis techniques and cell tests were performed in most of the studies. De Valence etal. went into more advanced in vivo tests by implanting plasma-activated electropun PCL scaffolds as a vascular graft (Figure 8). The corresponding studies are summarized in Table 2.

Table 2. Overview of literature on plasma activation on PCL electrospun fibers not discussed in the text

\begin{tabular}{|c|c|c|c|c|c|}
\hline Author & Year & $\begin{array}{l}\text { Reactor } \\
\text { and gas }\end{array}$ & $\begin{array}{l}\text { Physico-chemical } \\
\text { properties }\end{array}$ & Cell type & $\begin{array}{l}\text { Bioresponsive } \\
\text { properties }\end{array}$ \\
\hline $\begin{array}{c}\text { Prabhakaran } \\
\text { etal. [34] }\end{array}$ & 2008 & $\begin{array}{l}\text { RF low } \\
\text { pressure } \\
\text { air }\end{array}$ & $\begin{array}{c}\text { - enhanced } \\
\text { wettability } \\
\text { - incorporation of O- } \\
\text { containing groups } \\
\text { - decreased tensile } \\
\text { strength } \\
\text { - unmodified } \\
\text { elongation at break }\end{array}$ & $\begin{array}{l}\text { Schwann cells } \\
\text { (RT4-D6P2T) }\end{array}$ & $\begin{array}{l}\text { - better attachment } \\
\text { and proliferation } \\
\text { - expression of } \\
\text { bipolar elongations }\end{array}$ \\
\hline $\begin{array}{c}\text { Martins et al. } \\
\text { [87] }\end{array}$ & 2009 & $\begin{array}{l}\text { RF low } \\
\text { pressure } \\
\mathrm{O}_{2} \text { or } \mathrm{Ar}\end{array}$ & $\begin{array}{c}\text { - enhanced } \\
\text { wettability } \\
\text { - incorporation of } \mathrm{C}- \\
\mathrm{O}, \mathrm{C}=\mathrm{O} \text { and } \mathrm{O}-\mathrm{C}-\mathrm{O} \\
\text { groups }\end{array}$ & $\begin{array}{c}\text { - mouse } \\
\text { fibroblasts } \\
\text { (L929) } \\
\text { - human primary } \\
\text { osteosarcoma } \\
\text { cells (Saos-2) } \\
\text { - mouse } \\
\text { chondrocyte } \\
\text { teratocarcinoma } \\
\text { cells (ATDC5) }\end{array}$ & $\begin{array}{l}\text { better viability, } \\
\text { adhesion and } \\
\text { proliferation }\end{array}$ \\
\hline $\begin{array}{c}\text { Jahani et al. } \\
\text { [152] }\end{array}$ & 2012 & $\begin{array}{l}\mathrm{RF} \text { low } \\
\text { pressure } \\
\mathrm{O}_{2}\end{array}$ & $\begin{array}{c}\text { - enhanced } \\
\text { wettability } \\
\text { - reduced mechanical } \\
\text { strength }\end{array}$ & $\begin{array}{l}\text { mesenchymal } \\
\text { stem cells }\end{array}$ & better proliferation \\
\hline $\begin{array}{l}\text { De etal. } \\
\text { [153] }\end{array}$ & 2013 & $\begin{array}{l}\mathrm{RF} \text { low } \\
\text { pressure } \\
\mathrm{O}_{2}\end{array}$ & $\begin{array}{l}\text { - enhanced } \\
\text { wettability } \\
\text { - unchanged } \\
\text { mechanical strength } \\
\text { and elasticity }\end{array}$ & $\begin{array}{l}\text { primary porcine } \\
\text { smooth muscle } \\
\text { cells }\end{array}$ & $\begin{array}{l}\text { - elongated cell } \\
\text { morphology } \\
\text { - in vivo } \\
\text { implantation: } \\
\text { better } \\
\text { cellularization and } \\
\text { more dense and } \\
\text { extended cellular }\end{array}$ \\
\hline
\end{tabular}


Table 2. (continued)

\begin{tabular}{|c|c|c|c|c|c|}
\hline Author & Year & $\begin{array}{l}\text { Reactor } \\
\text { and gas }\end{array}$ & $\begin{array}{l}\text { Physico-chemical } \\
\text { properties }\end{array}$ & Cell type & $\begin{array}{l}\text { Bioresponsive } \\
\text { properties }\end{array}$ \\
\hline & & & & & $\begin{array}{l}\text { infiltrate in the } \\
\text { scaffold }\end{array}$ \\
\hline $\begin{array}{l}\text { Abbasi etal. } \\
\text { [154] }\end{array}$ & 2014 & $\begin{array}{c}\text { RF low } \\
\text { pressure } \\
\mathrm{O}_{2}\end{array}$ & $\begin{array}{c}\text { - enhanced } \\
\text { wettability } \\
\text { - decreased } \\
\text { mechanical strength } \\
\text { and elongation at } \\
\text { break }\end{array}$ & $\begin{array}{l}\text { mouse } \\
\text { embryonic stem } \\
\text { cells }\end{array}$ & better proliferation \\
\hline $\begin{array}{c}\text { Sharma et al. } \\
\text { [155] }\end{array}$ & 2014 & $\begin{array}{c}\text { atmosphe } \\
\text { ric } \\
\text { pressure } \\
\mathrm{He} / \mathrm{O}_{2}\end{array}$ & \begin{tabular}{|c} 
- enhanced \\
wettability \\
- unchanged \\
mechanical strength \\
- enhanced \\
transparency
\end{tabular} & $\begin{array}{c}\text { - human corneal } \\
\text { epithelial cells } \\
\text { - limbal } \\
\text { epithelial cells }\end{array}$ & $\begin{array}{c}\text { - better cell } \\
\text { adhesion and } \\
\text { proliferation } \\
\text { - cell morphology } \\
\text { showing abundant } \\
\text { microvilli } \\
\text { - retained cell } \\
\text { phenotype showed } \\
\text { by gene expression }\end{array}$ \\
\hline $\begin{array}{l}\text { Pappa et al. } \\
\text { [156] }\end{array}$ & 2015 & $\begin{array}{c}40 \mathrm{kHz} \\
\text { low } \\
\text { pressure } \\
\mathrm{O}_{2}\end{array}$ & $\begin{array}{c}\text { - enhanced } \\
\text { wettability } \\
\text { - incorporation of } \\
\mathrm{C}-0 \text { and C=0 groups } \\
\text { - modified roughness } \\
\text { - unchanged } \\
\text { mechanical } \\
\text { properties }\end{array}$ & $\begin{array}{c}\text { mouse } \\
\text { fibroblasts L929 }\end{array}$ & $\begin{array}{c}\text { enhanced viability, } \\
\text { adhesion and } \\
\text { proliferation }\end{array}$ \\
\hline $\begin{array}{l}\text { Receketal. } \\
\quad \text { [157] }\end{array}$ & 2016 & $\begin{array}{c}\mathrm{RF} \text { low } \\
\text { pressure } \\
\mathrm{O}_{2} \text { or } \mathrm{NH}_{3} \\
\text { or } \mathrm{SO}_{2}\end{array}$ & $\begin{array}{c}\text { - incorporation of: } \\
\mathrm{C}-\mathrm{O}, \mathrm{C}=\mathrm{O}, \mathrm{O}=\mathrm{C}-\mathrm{O}, \mathrm{C}-\mathrm{S} \\
\left(\mathrm{SO}_{2} \text { plasma }\right), \mathrm{C}-\mathrm{N} \\
\text { and } \mathrm{O}=\mathrm{C}-\mathrm{N}\left(\mathrm{NH}_{3}\right. \\
\text { plasma) groups }\end{array}$ & $\begin{array}{l}\text { human umbilical } \\
\text { endothelial cells }\end{array}$ & $\begin{array}{c}\text { - enhanced } \\
\text { adhesion and } \\
\text { proliferation }\left(\mathrm{O}_{2}\right. \\
\left.\text { and } \mathrm{NH}_{3} \text { plasmas }\right) \\
\text { - elongated cell } \\
\text { morphology }\end{array}$ \\
\hline $\begin{array}{c}\text { Yari etal. } \\
\text { [70] }\end{array}$ & 2016 & $\begin{array}{c}\text { low } \\
\text { pressure } \\
\mathrm{O}_{2}\end{array}$ & - & $\begin{array}{c}\text { rat nestin- } \\
\text { positive hair } \\
\text { follicle stem cells }\end{array}$ & $\begin{array}{l}\text { good adhesion and } \\
\text { proliferation }\end{array}$ \\
\hline
\end{tabular}



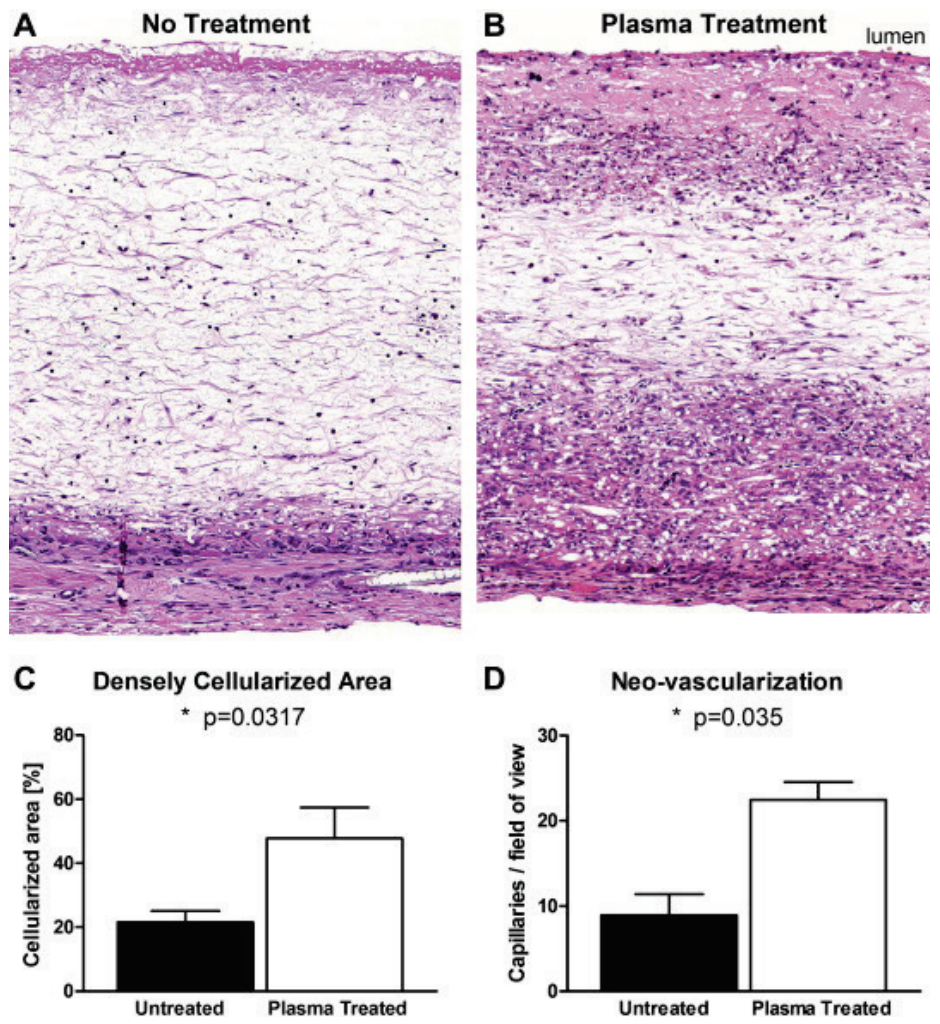

Figure 8. Vascular implantation of untreated and plasma-treated electrospun PCL grafts. Improvement of the cellular invasion in the plasma-treated graft wall (B) compared to the untreated graft (A). Significant improvement of the densely cellularized area (C) and the number of capillaries (D) in the graft wall after plasma treatment [153]. Copyright $\odot 2013$ with permission from Elsevier.

Two very recent studies integrating novel biomimetic scaffolds with atmospheric plasma activation showed interesting results in stimulating tissue regeneration. Zhu et al. developed a PCL electrospun mat on which PLGA microspheres containing TGF- $\beta 1$ and bovine serum albumin were distributed to induce chondrogenesis. The scaffolds were then subjected to an atmospheric He plasma that decreased their WCA by $61 \%$ leading to an enhanced proliferation of primary mesenchymal stem cells (MSCs) (Figure 9). An improved cell infiltration capacity on the treated scaffolds was detected by immunofluorescence microscopy. Moreover, after maintaining the seeded scaffolds in a chondrogenic media, significantly enhanced GAG production and collagen synthesis were detected on the plasma-treated samples compared to the untreated samples thus revealing the differentiation of MSCs into a chondrogenic lineage [15]. Another biomimetic electrospun scaffold involving the layer-by-layer approach was fabricated by Surucu et al. for L929 fibroblast cultivation. Three layers were successively electrospun on top of each other: 
PCL/Chitosan/PCL. A plasma treatment was applied by using a DBD operating in $\mathrm{Ar}+\mathrm{N}_{2}$ or $\mathrm{Ar}+\mathrm{O}_{2}$ at atmospheric pressure. $\mathrm{Ar}+\mathrm{N}_{2}$ plasma was unable to significantly enhance the wettability of the fibers, thus $\mathrm{Ar}+\mathrm{O}_{2}$ atmosphere was used for subsequent experiments. A combination of O-group incorporation and nanoroughness change resulted in an improved cellular performance in terms of adhesion, viability and proliferation [158].

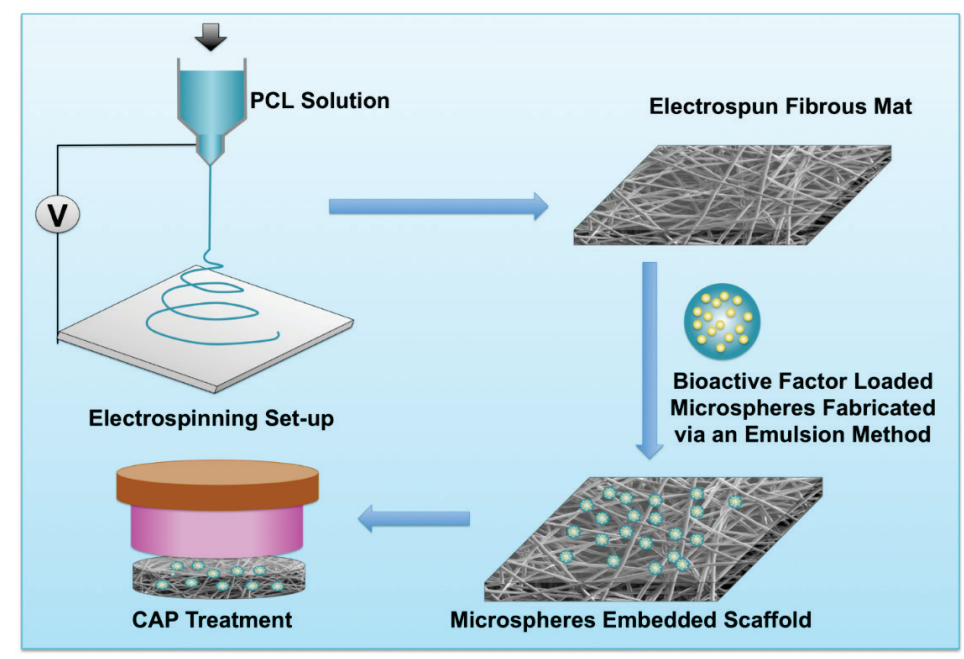

Figure 9. Schematic illustration of embedding PLGA microspheres on PCL electrospun fibers and cold atmospheric plasma (CAP) modification for cartilage TE (Open access).

[15]

\subsubsection{PLLA fibers}

After PCL, the second most plasma-activated electrospun scaffolds for TE applications are PLLA nanofibers. One of the first attempts conducted by Corey etal. and aiming to improve the behavior of neurons cultured on plasma-treated PLLA fibers was unsuccessful. Air plasma treatment worsened the survival of primary motor neurons when seeded at low densities on PLLA fibers despite that it decreased the mat's WCA from $63^{\circ}$ to $32^{\circ}$. Since this undesirable effect was not observed on untreated scaffolds, one can conclude that plasma treatment negatively altered the fiber chemistry and/or morphology which reduced cellular viability. Therefore, plasma process parameters should be selected more carefully based on a detailed chemical and physical surface analysis characterizing what changes are occurring and to what extent, which was absent in this study [137]. The subsequent studies involving a plasma activation of PLLA fibers presented very promising results in enhancing tissue regeneration. Low pressure RF systems were used to create plasma discharges in different working gas atmospheres: $\mathrm{O}_{2}$, $\mathrm{Ar}$ and $\mathrm{Ar}-$ 
$\mathrm{NH}_{3} / \mathrm{H}_{2}$. The hydrophobic PLLA fibers having WCA values above $115^{\circ}$ were switched to superhydrophilic fibers with WCA values depending on the working conditions (used gas, treatment time and power). XPS measurements revealed an incorporation of 0 -containing groups $(\mathrm{C}-\mathrm{O}, \mathrm{C}=\mathrm{O}$ and $\mathrm{O}-\mathrm{C}=\mathrm{O})$ for all plasma treatments with an additional incorporation of $\mathrm{N}$-containing groups on the fibers treated by $\mathrm{Ar}-\mathrm{NH}_{3} / \mathrm{H}_{2}$ plasma. In this last case, trifluoromethyl benzaldehyde (TFBA) derivatization particularly demonstrated the incorporation of $\mathrm{NH}_{2}$ groups. As a result of these surface modifications, Liu etal. detected an improved adhesion of porcine mesenchymal stem cells on $\mathrm{O}_{2}$ plasma-treated fibers while Correia etal. showed a good metabolic activity of MC3T3-E1 cells when cultured on $\mathrm{Ar}$ or $\mathrm{O}_{2}$ plasma-treated fibers $[159,160]$. Cheng etal. demonstrated that argon plasma treatment is very efficient in improving the proliferation of bovine aorta endothelial cells (BAECs) and bovine smooth muscles cells (BSMCs) while $\mathrm{Ar}-\mathrm{NH}_{3} / \mathrm{H}_{2}$ plasma treatment is more efficient in enhancing their spreading on PLLA fibers. The visualization of the scaffold cross sections by fluorescent microscopy after DAPI staining revealed that both plasma treatments are efficient in improving BAEC infiltration into the scaffolds. Invivo subcutaneous implantation of PLLA scaffolds under rat skin also enhanced the cellular infiltration when plasmatreated [161]. Atmospheric pressure plasma was also employed to activate PLLA fibers and similar surface analysis techniques and cell tests were conducted. Liu etal. increased the amino group content and thus enhanced the wettability of PLLA fibers by placing them in a plasma cleaner and treating them for different plasma exposure times. In addition to cell proliferation tests, showing a greater performance of bone marrow stem cells on plasma-treated fibers, quantitative reverse transcription-polymerase chain reaction (qRTPCR) analysis was performed to assess the expression of osteogenic-specific genes. The treated nanofibers promoted high levels of osteogenic gene expression accompanied with an excessive ALP activity thus revealing the differentiation of the cells towards an osteogenic lineage. Therefore plasmatreated PLLA nanofibers are promising candidates for bone regeneration [162]. Dolcietal. plasma-treated PLLA nanofibers using a linear corona discharge system operating in air at atmospheric pressure. A significantly greater wettability is attained (WCA: $120^{\circ}-20^{\circ}$ ) correlating with the detected incorporation of $\mathrm{COOH}$ groups. In order to assess the amount of $\mathrm{COOH}$ incorporated on the fibers, a chemical derivatization and conjugation with fluorescein isothiocyanate (FITC) is performed followed by a measurement of the fluorescence intensity. When cultured on plasma-treated fibers, mouse embryonic fibroblasts exhibited a dendritic-like and more elongated morphology compared to cells grown on untreated fibers [144]. 


\subsubsection{PLGA fibers}

Despite the excessive use of electrospun PLGA nanofibers in a wide range of TE applications, the modification of their surface by plasma treatment is still overlooked in literature. Parketal. are one of the rare groups, if not the only one, that considered studying the plasma activation of PLGA fibers. They published 3 papers in which a Miniplasma-station ${ }^{\circledR}$ operating in $\mathrm{O}_{2}$ and $\mathrm{NH}_{3}$ at low pressure was used to activate PLGA nanofibers. The first paper was restricted to a physico-chemical surface analysis. A loss of the nanofibrous structure was observed after an exposure to $\mathrm{O}_{2}$ plasma for $180 \mathrm{~s}$. However the fibers retained their morphology and dimension when exposed to $\mathrm{NH}_{3}$ plasma. An enhanced wettability was detected by the decrease of the WCA from $139^{\circ}$ to $112^{\circ}$ and $47^{\circ}$ after $\mathrm{O}_{2}$ and $\mathrm{NH}_{3}$ plasma treatment respectively. The WCA results correlate with the XPS measurements that revealed a slight increase in the $0 / C$ ratio after $\mathrm{O}_{2}$ plasma exposure and a significant increase in the $\mathrm{N} / \mathrm{C}$ ratio after $\mathrm{NH}_{3}$ plasma treatment [163]. In the second paper, in addition to a more detailed surface analysis, the authors investigated the degradation of the fibers invitro as well as their bioresponsive properties using mouse NIH 3T3 fibroblasts. When incubated in phosphate buffered saline solution for 2 weeks, plasma-treated fibers showed a much faster degradation than untreated fibers. A well-controlled degradation rate is critical in TE and should be therefore reconsidered after plasma treatment. An enhanced cell adhesion and proliferation were detected after the surface activation especially on the $\mathrm{NH}_{3}$ plasma-treated samples [116]. Based on the obtained results, in the third study, the fibers were only treated with $\mathrm{NH}_{3}$ plasma and the expression of Bcl2 and heat shock protein (HSP) in the cultured fibroblasts was assessed by RTPCR as a function of N-density and wettability. It is well known that HSP genes are expressed when cells are subjected to various types of stress while Bcl-2 expression is reduced when a stress apoptotic pathway occurs. A prominent expression of HSP was detected on untreated and plasma-treated fibers having the lowest WCA with almost no expression of Bcl-2 genes. Inversed gene expression levels was perceived on fibers having a WCA around $51^{\circ}$. Therefore, a moderate hydrophilicity is favorable for the cells as it suppressed the cellular stress which was in accordance with an enhanced cell viability as shown by a dead/live staining assay [164].

\subsubsection{Plasma polymerization and grafting}

A thin polymeric film-forming approach involving a plasma exposure refers to as plasma polymerization and is chemically different from the conventional wet-chemical polymerization. The former can be defined as a radical polymerization in which propagating reactions between monomers and a polymeric substrate are initiated by radical species at the polymer surface while the latter is known as an ionic polymerization involving chemical reactions generated by ionic species [165]. During plasma polymerization, liquid or gaseous monomers are exposed to the reactive plasma and are 
therefore converted into reactive components that recombine to the substrate initiation sites also induced by the plasma exposure. As a consequence, an amorphous highly branched and cross-linked nm-thick polymer film is deposited on the substrate. Plasma polymers are generally characterized by a high stability and density, a great adhesion to a variety of substrates, a chemical inertia, a mechanical toughness and a pinhole-free structure [41,43]. All these characteristics are extensively influenced by a set of parameters used during the plasma process [33]. Although extensively used in TE applications, this solvent-free deposition technique is mainly limited to non-electrospun scaffolds since optimizing all the plasma parameters in order to simultaneously obtain a stable coating while preserving the delicate structure of nanofibers remains a major challenge. Few authors succeeded to attain this goal and highlighted the importance of this promising technique in enhancing the performance of specific cell types when cultured on nanofibers $[74,166,167]$.

Plasma grafting is a two-phase technique of which the first phase requires a plasma exposure while the second phase involving a direct contact with a (macro)monomer occurs post-plasma irradiation. The plasma treatment introduces, as described above, reactive groups on the polymer surface serving afterwards as initiation sites for direct radical vinyl polymerization or for covalent immobilization of biomolecules which involves a wet-chemical step. The resulting coating is characterized by a high stability and functional specificity $[33,43,135]$. The synchronic effect of electrospinning and plasma grafting was recently associated with several advances in the TE field. This was illustrated by the significant enhancement of several cellular activities when plasma grafts biomolecules such as ECM components and growth factors on nanofibers [13,71]. Both plasma grafting and plasma polymerization techniques are considered superior to the plasma activation in terms of ageing effect.

\subsubsection{Plasma polymerization and grafting applied on nanofibers in TE applications}

\subsubsection{PCL fibers}

In addition to the simple plasma activation, plasma grafting of bioactive molecules on electrospun PCL fibers was studied and showed great achievements in different TE fields. Vascular TE was one of the first fields in which plasma grafting applied on PCL fibers was investigated. Electrospun biodegradable polymers were being used to fabricate tubes that can be implanted in the body as vascular substitutes. Seeding endothelial cells (ECs) onto the tubes can help to prevent intimal hyperplasia after implantation since these cells release factors that control fibrinolysis and thrombogenesis 
$[168,169]$. However ECs are often detached from the graft surface when exposed to blood circulation. Grafting ECM proteins on the material surface was shown to favor the cell attachment. Therefore, in 2005, Ma etal. subjected PCL nanofibers to an RF air plasma in order to introduce $\mathrm{COOH}$ groups onto their surface for subsequent grafting of gelatin. Toluidine blue 0 , a dye that can specifically combine with carboxyl groups, was used and showed that increasing the plasma exposure time and the electrospun mat thickness is associated with an increase in the $\mathrm{COOH}$ density. Water-soluble carboiimide was employed to activate $\mathrm{COOH}$ groups which served as binding sites for gelatin. Human coronary artery endothelial cells (HCAECs) kept a rounded morphology when cultured on untreated fibers, while they became totally spread with the formation of pseudopods on gelatin-grafted fibers. Moreover, MTS assay showed an enhanced proliferation on the treated fibers and immunostaining assay revealed that the proliferating cells retained their phenotype as they expressed 3 characteristics markers: vascular cell adhesion molecule 1, intercellular adhesion molecule 1 and platelet-endothelial cell adhesion molecule 1. Therefore gelatin plasma-grafted PCL fibers are promising candidates in blood vessel TE [120]. In the same year, this research group thought of testing of efficiency of collagen coating in the endothelialization of electrospun nanofibers. In order to control the degradation rate of the nanofibers, PCL was replaced by the copolymer P(LLA$\mathrm{CL}$ ). After subjecting the fibers to an almost similar plasma treatment, the fibers were immersed in a collagen solution then dried. XPS and BCA protein assay confirmed the immobilization of a good amount of collagen on the fibers and rhodamine staining showed an excellent distribution throughout the scaffold. Similar cell tests were performed and showed more or less the same positive results which also highlights the potential of collagen plasma-grafted fibers to serve as vascular grafts [170]. In 2014, Guex et al. conducted 2 studies in which PCL fibers were coated with a CHO-type layer rich with ester bonds using an $\mathrm{RF}$ plasma process $\left(\mathrm{C}_{2} \mathrm{H}_{4} / \mathrm{CO}_{2} / \mathrm{Ar}\right)$. In the first study, vascular endothelial growth factors (VEGF) were immobilized on the plasma-coated fibers to study the behavior of primary and immortalized human umbilical vein endothelial cells (HUVECs). EDC/NHS (1-ethyl-3-(3-dimethylaminopropyl) carbodiimide/ $N$-hydroxysuccinimide) based coupling chemistry was adopted to convert the incorporated $\mathrm{COOH}$ groups into amine reactive ester groups used to covalently couple VEGF by creating amide bonds. An additional linker molecule was added to this functionalization route in order to diminish the steric hindrance during protein immobilization. The biological integrity of VEGF was maintained after the grafting as shown by immunohistochemistry assay using anti-VEGF antibodies. The functionalized fibers induced a higher number of primary and immortalized cells, 9 days after culturing, compared to untreated fibers. Thus, these growth factor-loaded nanofibers can also provide successful scaffolds for vascular TE [119]. In the second study, the CHO-coated PCL fibers were used to repair damaged myocardium. Bone-marrow-derived mesenchymal stem cells were seeded on the scaffolds that were subsequently 
implanted into a rat model of chronic myocardial infraction. Echocardiograms and histological evaluation of the implanted scaffolds revealed a steadied cardiac function associated with a diminished dilatation in case of the plasmacoated scaffolds. Moreover, a significant decrease in the ejection fraction and the fractional shortening was observed 4 weeks after implantation in the group implanted with the plasma-coated scaffolds compared to the control group [112]. These results demonstrate that optimized PCL electrospinning associated with plasma grafting and polymerization can allow translational research in the cardiovascular field.

Bone TE also experienced some advances when adopting plasma grafting and polymerization to functionalize PCL fibers serving as bone grafts. For instance, Yang etal. subjected PCL fibers to an RF plasma treatment using a plasma cleaner operating in argon at low pressure. Then the plasma-treated fibers were immersed in a simulated body fluid (SBF) for immobilization of CaP. After $2 \mathrm{~h}$ of immersion, a coating composed of nanoapatite and dicalcium phosphate apatite was found to cover the fibers with the preservation of the porous structure. A continuous immersion in SBF for a week transformed the coating into pure calcium with nanocrystallinity closely comparable to the biological apatite. The obtained scaffold is expected to serve as a successful cell carrier promoting bone regeneration [171]. Recently, Ko et al. investigated the plasma deposition of acid rich coating on PCL nanofibers and the performance of preosteoblasts MC3T3-E1 when seeded on such fibers. An argon low pressure RF plasma was applied followed by a plasma polymerization phase using acrylic acid as precursor. XPS measurements showed an increase in the $\mathrm{O} / \mathrm{C}$ ratio from 0.30 to 0.34 , accompanied with an enhanced wettability. MTT assay revealed an improved cell proliferation on the plasma-coated fibers with a greater alkaline phosphatase activity suggesting a successful differentiation towards osteoblastic lineage [166].

In addition to the cardiovascular and bone TE, the potential of plasma-coated PCL fibers in improving nerve regeneration was also explored. Zander etal. published 2 papers in which neurite outgrowth on PCL fibers was studied. In the first paper, collagen and laminin were used to functionalize the fibers by physical adsorption or covalent attachment chemistries. Prior to the covalent attachment, fibers were subjected to air RF plasma treatment at low pressure to introduce carboxylic groups onto the fiber surface. EDC/NHS based coupling chemistry was then adopted to graft collagen and laminin on the fibers. Concerning the physical adsorption, the fibers were directly incubated in laminin and collagen solutions. After seeding PC12 neuron-like cells on the fibers, neurite outgrowth was visualized by confocal microscopy after actin staining. Cells grown on the modified fibers exhibited significantly longer neurites than the cells cultured on untreated fibers. Among the proteinmodified scaffolds, shorter neurites are observed on the collagen plasmacoated fibers. This is suggestive of an altered collagen conformation after covalent attachment or low protein content on the fibers. The bioavailability of 
the laminin-coated fibers was tested by an immunofluorescence assay using anti-laminin antibodies and no difference was observed between the physically adsorbed and the covalently attached laminin. The covalent chemistry did not alter the laminin conformation or reduce its activity which makes from the plasma-coating of laminin a suitable method for enhancing nerve regeneration [29]. Therefore, in their second paper, the authors plasma-coated PCL fibers with laminin and studied the effect of the incorporated protein amount on the neurite outgrowth. The protein concentration was assessed by several methods (XPS, UV spectroscopy and fluorescence-based assays) and longer neurites were observed on fibers containing higher concentrations of laminin [172].

Some authors studied the bioresponsive properties of plasma-coated PCL fibers and demonstrated their efficiency in tissue regeneration without being limited to a TE field in particular. Jia etal. immobilized soluble eggshell membrane proteins (SEP) on PCL fibers by treating them with low pressure RF argon plasma and immersing them in SEP solution. They expected a great potential of these fibers in TE applications since the eggshell membrane is to some extend very similar to the ECM. It contains several proteins such as collagen type I, $\mathrm{V}$ and $\mathrm{X}$ that play an important role in the development of the embryo and the mineralization of the eggshell. Human dermal fibroblasts were seeded on the SEP-coated fibers. MTT assay, SEM and confocal microscopy revealed a significant improvement in cellular attachment, spreading and proliferation which confirmed the hypothesis of the authors (Figure 10) [173]. Safaeijavan etal. studied the behavior of fibroblasts on gelatin plasma-coated PCL fibers. The fibers were subjected to an oxygen plasma treatment using a low frequency $(40 \mathrm{kHz})$ plasma generator operating at low pressure then a covalent immobilization of gelatin was performed by carbodiimide wet chemistry. MTT assay showed an enhanced cellular viability and proliferation on the treated fibers [174]. Very recently, Cohn et al. adopted a new strategy to functionalize electrospun PCL fibers. First, an air plasma treatment at low pressure was applied then the plasma-treated fibers were immersed in a solution containing cholesteryl succinyl silane (CSS). CSS vesicles were therefore immobilized on the fibers then ruptured and fused into a lipid bilayer. CSS immobilization on the plasma-treated fibers was confirmed by a fluorescent probe for lipid bilayers and by Raman spectroscopy. Then antiCD20 were immobilized on the CSS to biologically functionalize the fibers with a high cell specificity. After seeding Granta-22 B lymphoma cells, anti-CD20 functionalized fibers were shown to capture the cells 2.4 times more than the untreated fibers. Important TE applications may thus be improved by this lipid-mediated protein functionalization of nanofibers [108]. 

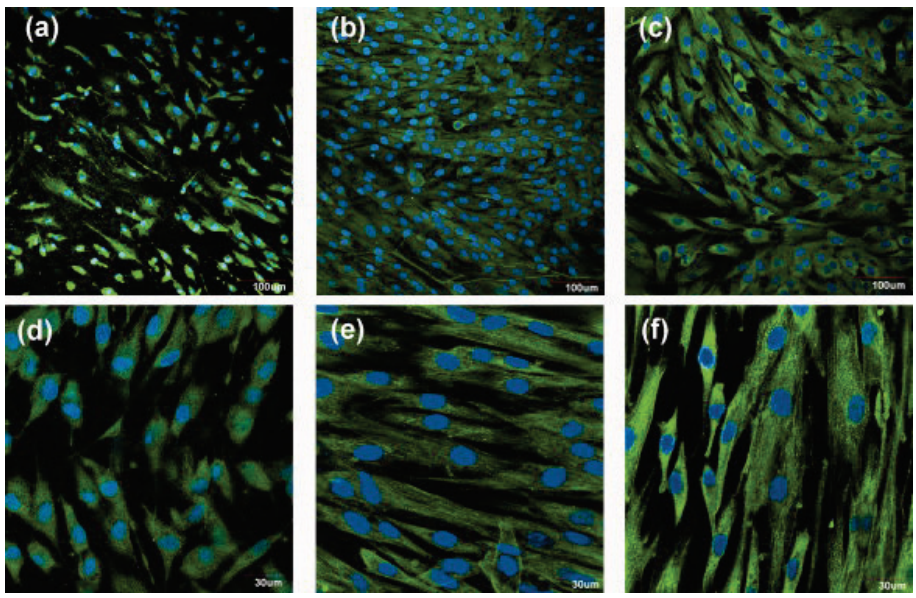

Figure 10. Morphology of cytoskeleton and nuclei of fibroblasts cultured on (a,d) untreated PCL nanofibers, (b, e) SEP plasma-modified PCL nanofibers, and (c, f) glass

coverslips after 3 days. F-actin microfilaments are visualized by phalloidin-FITC (green). Cell nuclei are visualized by Hoechst 33258 (blue). The fibers are visualized by auto-fluorescence [173]. Copyright $\odot 2007$ with permission from Wiley.

\subsubsection{PLLA fibers}

Several plasma polymerization and grafting strategies were also applied on electrospun PLLA nanofibrous scaffolds in order to be effectively used in bone, blood vessel, liver, cartilage, nerve and other TE applications. Parketal. were one of the first groups to investigate plasma polymerization of acrylic acid on nanofibers. In 2 papers, published in 2006 and 2007, they subjected PLLA fibers to a simultaneous low pressure oxygen plasma treatment and in situ acrylic acid polymerization for $30 \mathrm{~s}$ using an RF glow discharge device. In the first paper PLLA films were also tested while in the second study PGA and PLGA fibers were explored. In all cases, no significant morphological or mechanical (tensile strength and elongation-at-break) difference was perceived after the treatment. A decreased WCA associated with an incorporation of O-containing functionalities such as $\mathrm{COOH}$ were detected on the fibers by performing ESCA measurements and toluidine blue 0 assay. MTT assay showed an enhanced proliferation of NIH 3T3 fibroblasts when cultured on the acrylic acid-grafted scaffolds for 6 days $[74,167]$.

In 2008 , Koh etal. conducted a comparative study about neuron viability and outgrowth on PLLA fibers functionalized with laminin by means of three different methods. In the first 2 methods, the fibers were subjected to an RF plasma treatment using a plasma cleaner operating in air. Afterwards, a covalent binding of laminin was performed on some of the plasma-treated fibers based on the EDC/NHS coupling chemistry, while a physical adsorption of laminin was done on the other plasma-treated fibers by simply immersing 
them in a laminin solution. In the third method, laminin was blended with the PLLA solution prior to the electrospinning. MTS assay showed that lamininPLLA nanofibers supported better neuron-like PC12 cell viability compared to untreated fibers. Moreover, laminin was able to promote axonal extensions as revealed by immunohistochemistry assay with extensive neurite outgrowth particularly on the blended laminin-PLLA fibers containing more laminin. This suggests that the high voltage of the electrospinning and the solvent (HFP) did not adversely affect the laminin bioactivity. Therefore, plasma functionalization was in this case less efficient than the blending method in enhancing nerve regeneration [30]. Recently, unsatisfying neurite outgrowth results were also obtained by Schaub etal. when applying a plasma grafting of different molecules on electrospun PLLA fibers. An RF oxygen plasma treatment was carried out on the PLLA fibers that were subsequently modified by EDC/NHS to covalently bind diethylnetriamine (DTA) for amine functionalization, 2-(2-aminoethoxy)ethanol (AEO) for alcohol functionalization or GRGDS sequences as bioactive ligands interacting with integrins. Unexpectedly, the untreated fibers exhibited the best neurite outgrowth after culturing chick dorsal root ganglia. The longest neurites were detected on untreated fibers followed by fibers containing GRGDS. Shorter neurites were observed on plasma-treated fibers and on fibers functionalized with DTA and significantly short neurites were detected on fibers grafted with AEO. These results suggest that neurite extension needs a very specific surface functionalization using adequate bioactive ligands rather than a randomly increased hydrophilicity [175]. When it comes to bone, liver, cartilage and blood vessel TE, several studies have recently shown that combining PLLA electrospinning with plasma surface grafting of biomolecules was rather very promising. These studies and their general results will be summarized in Table 3.

Table 3. Overview of literature on plasma grafting on electrospun PLLA fibers not discussed within the text

\begin{tabular}{c|c|c|c|c|c|c}
\hline Author & Year & $\begin{array}{c}\text { Reactor and } \\
\text { gas }\end{array}$ & Precursor & Cell type & Effect & $\begin{array}{c}\text { Potential } \\
\text { application }\end{array}$ \\
\hline $\begin{array}{c}\text { Paletta etal. } \\
{[176]}\end{array}$ & 2010 & $\begin{array}{c}\text { RF low } \\
\text { pressure } \mathrm{O}_{2}\end{array}$ & $\begin{array}{c}\text { cyclic RGD } \\
\text { grafted } \\
\text { (EDC/NHS } \\
\text { coupling } \\
\text { chemistry) }\end{array}$ & $\begin{array}{c}\text { human } \\
\text { mesenchymal } \\
\text { stem cells }\end{array}$ & $\begin{array}{c}\text { - no enhanced } \\
\text { proliferation and cell } \\
\text { density because of } \\
\text { limited RGD densities } \\
\text { - differentiation } \\
\text { towards osteoblastic } \\
\text { lineage }\end{array}$ & bone TE \\
$\begin{array}{c}\text { Seyedjafari } \\
\text { etal. [104] }\end{array}$ & 2010 & $\begin{array}{c}\text { MW low } \\
\text { pressure } 0_{2}\end{array}$ & $\begin{array}{c}\text { nanohydrox } \\
\text { yapatite } \\
\text { grafted }\end{array}$ & $\begin{array}{c}\text { unrestricted } \\
\text { somatic stem } \\
\text { cells }\end{array}$ & $\begin{array}{c}\text { - enhanced attachment, } \\
\text { spreading and } \\
\text { proliferation } \\
\text { - efficient }\end{array}$ & bone TE \\
\hline
\end{tabular}


Table 3. (continued)

\begin{tabular}{|c|c|c|c|c|c|c|}
\hline Author & Year & $\begin{array}{c}\text { Reactor and } \\
\text { gas }\end{array}$ & Precursor & Cell type & Effect & $\begin{array}{c}\text { Potential } \\
\text { application }\end{array}$ \\
\hline & & & & & $\begin{array}{c}\text { osteogenic lineage: } \\
\text { high ALP activity, } \\
\text { biomineralization and } \\
\text { expression of bone- } \\
\text {-related genes } \\
\text { - in vivo subcutaneous } \\
\text { implantation: } \\
\text { ossification and } \\
\text { formation of trabeculi }\end{array}$ & \\
\hline $\begin{array}{c}\text { Chen etal. } \\
\text { [26] }\end{array}$ & 2011 & \begin{tabular}{|c|} 
DC pulsed \\
system low \\
pressure $\mathrm{O}_{2}$
\end{tabular} & $\begin{array}{l}\text { cationized } \\
\text { gelatin } \\
\text { grafted } \\
\text { (EDC } \\
\text { coupling } \\
\text { chemistry) }\end{array}$ & $\begin{array}{c}\text { rabbit } \\
\text { articular } \\
\text { chondrocytes }\end{array}$ & $\begin{array}{l}\text { - enhanced viability, } \\
\text { proliferation and } \\
\text { differentiation : } \\
\text { improved collagen and } \\
\text { glycosaminoglycan } \\
\text { secretion and } \\
\text { expression of } \\
\text { chondrocyte markers } \\
\text { - in vivo subcutaneous } \\
\text { implantation: } \\
\text { Formation of ectopic } \\
\text { cartilaginous tissue }\end{array}$ & $\begin{array}{c}\text { cartilage } \\
\text { TE }\end{array}$ \\
\hline $\begin{array}{c}\text { Ghaedi etal. } \\
\text { [177] }\end{array}$ & 2012 & $\begin{array}{c}\text { MW low } \\
\text { pressure } \mathrm{O}_{2}\end{array}$ & $\begin{array}{l}\text { collagen } \\
\text { grafted } \\
\text { (EDC/NHS } \\
\text { coupling } \\
\text { chemistry) }\end{array}$ & $\begin{array}{l}\text { human bone- } \\
\text {-marrow } \\
\text { derived } \\
\text { mesenchymal } \\
\text { stem cells }\end{array}$ & $\begin{array}{l}\text { efficient differentiation } \\
\text { into hepatocyte } \\
\text { lineage: high } \\
\text { expression of liver- } \\
\text {-specific markers such } \\
\text { as } \alpha \text {-fetoprotein, } \\
\text { albumin and } \\
\text { cytokeratins } 8 \\
\end{array}$ & liver TE \\
\hline $\begin{array}{c}\text { Seo etal. } \\
\text { [178] }\end{array}$ & 2013 & \begin{tabular}{|c|} 
DC \\
atmospheric \\
pressure He
\end{tabular} & $\begin{array}{l}\text { fibronectin } \\
\text { adsorption }\end{array}$ & - & $\begin{array}{c}\text { deep penetration of the } \\
\text { fibronectin in the } \\
\text { nanofibrous matrix }\end{array}$ & $\mathrm{TE}$ \\
\hline $\begin{array}{c}\text { Cheng etal. } \\
{[14]}\end{array}$ & 2014 & $\begin{array}{c}\text { RF low } \\
\text { pressure } \\
\text { Ar- } \mathrm{NH}_{3} / \mathrm{H}_{2}\end{array}$ & $\begin{array}{l}\text { heparin } \\
\text { grafted } \\
\text { (EDC/NHS } \\
\text { coupling } \\
\text { chemistry) }\end{array}$ & $\begin{array}{l}\text { bovine aorta } \\
\text { endothelial } \\
\text { cells }\end{array}$ & $\begin{array}{c}\text { enhanced cellular } \\
\text { infiltration through the } \\
\text { nanofibrous scaffold }\end{array}$ & $\begin{array}{c}\text { blood } \\
\text { vessel TE }\end{array}$ \\
\hline
\end{tabular}




\subsubsection{PLGA fibers}

Plasma polymerization and grafting strategies were rarely applied on electrospun PLGA scaffolds despite the promising results obtained when plasma functionalizing PLLA and PCL fibers. In 2010, Park etal. indirectly used plasma to graft PLGA fibers on polyurethane (PU) films. This was done by electrospinning PLGA fibers on PU films previously subjected to an atmospheric pressure MW plasma treatment operating in argon. The whole PU/PLGA scaffolds were then again plasma-treated to crosslink the PLGA fibers. After culturing human umbilical vein endothelial on the scaffold, MTT assay revealed a better adhesion and proliferation on PU/PLGA compared to PU scaffolds thus highlighting the importance of the grafted fibers. Moreover, a significantly enhanced adhesion was particularly detected on the plasmatreated PU/PLGA scaffolds thus highlighting the importance of the plasma. Therefore, such scaffolds can be considered, after in-depth studies, for their use as vascular grafts [179]. In 2012, Meade et al. plasma functionalized PLGA fibers to afford biological and topographical cues to regulate plurilpotent stem cells (PSCs) fate. Therefore, in a first step allylamine was plasma-polymerized on the fiber by using a low pressure RF plasma generator. Then the fibers were incubated in heparan sulfate (HS) solutions. The allylamine coating was found to immmobilize HS on the fibers with a retained ligand binding capacity. HS is a GAG that modulates the activity of wide-ranging growth factors and cytokines thus particularly controlling various signaling pathways directing PSCs behavior. HS-deficient mouse embryonic stem cells seeded on the treated fibers were successfully differentiated into neuronal lineage when adding the fibroblast growth factor 4 (FGF4) suggesting that the growth factor is activated by the immobilized HS on the fibers [180].

\subsection{CONCLUSION}

In this chapter, a quite extensive overview has been given on the literature involving a joint use of electrospinning and non-thermal plasma surface modification technologies for TE applications. In the past decade, electrospinning of synthetic biodegradable nanofibers has experienced a steep continuous rise due to their structural resemblance to the ECM. In parallel, plasma surface engineering techniques were been widely investigated to functionalize these nanofibers thus also mimicking the biological role of the ECM. Plasma activation, polymerization and grafting of bioactive molecules applied on electrospun scaffolds have shown great improvement in supporting various cell types that attached, proliferated, migrated and differentiated more efficiently compared to the untreated scaffolds. These results revealed that plasma is a powerful tool in enhancing bone, nerve, blood vessel, liver, cartilage and other tissue regeneration and should be therefore adopted by every tissue engineer. In the next few years, more attention should be given 
concerning the effects of the surface modification on the molecular processes induced in different cell types such as gene expression analysis. This will give more insights on how to specifically optimize the plasma process parameters for each cell type or tissue to be regenerated. Moreover, a translation from in vitro tests to in vivo tests should be more considered to pave the ways for the use of patient-customized electrospun scaffolds in humans suffering from tissue loss or failure.

\section{REFERENCES}

1. F.J. O'Brien. Mater. Today 14 (2011) 88-95.

2. $\quad$ F.G. Heineken,R. Skalak. J. Biomech. Eng-T. Asme 113 (1991) 111-112.

3. J. Black. Biomaterials 9 (1988) 379-379.

4. R. Langer,J. Vacanti. Science 260 (1993) 920-926.

5. L.S. Nair, S. Bhattacharyya. Nanotechnologies for the Life Sciences, Wiley, Weinheim, Germany, 2007, p. 1.

6. Y. Kim, H. Ko. Int. Neurourol. J. 20 (2016) S23-S29.

7. P. Supaphol, O. Suwantong. Biomedical Applications of Polymeric Nanofibers, Springer, Belin Heidelberg, Germany, 2011, p. 213.

8. $\quad$ B.D. Ulery, L.S. Nair. J. Polym. Sci. B Polym. Phys. 49 (2011) 832-864.

9. M. Sokolsky-Papkov, K. Agashi. Adv. Drug Deliv. Rev. 59 (2007) 187-206.

10. H.K. Kleinman, D. Philp. Curr. Opin. Biotechnol. 14 (2003) 526-532.

11. A. Rainer, M. Centola. Int. J. Artif. Organs 33 (2010) 76-85.

12. D. Yan, J. Jones. J. Biomed. Mater. Res. A 101 (2013) 963-972.

13. M. Tallawi, E. Rosellini. J. R. Soc. Interface 12 (2015) 1-24.

14. Q. Cheng, K. Komvopoulos. J. Biomed. Mater. Res. A 102 (2014) 1408-1414.

15. W. Zhu, N.J. Castro. Plos One 10 (2015) 1-18.

16. E.S. Place, J.H. George. Chem. Soc. Rev. 38 (2009) 1139-1151.

17. C. Frantz, K.M. Stewart. J. Cell Sci. 123 (2010) 4195-4200.

18. A. Curtis, C. Wilkinson. Mater. Today 4 (2001) 22-28.

19. A.J. García. Biomaterials 26 (2005) 7525-7529.

20. A.D. Bershadsky, C. Ballestrem. Eur. J. Cell Biol. 85 (2006) 165-173.

21. KhanAcademy, https://www.khanacademy.org/science/biology/structure-ofa-cell/cytoskeleton-junctions-and-extracellular-structures/a/theextracellular-matrix-and-cell-wall (09-2016).

22. S. Badylak, T. Gilbert. Tissue Eng. 1 (2008) 121-143.

23. H. Patel, M. Bonde. Trends Biomater. Artif. Organs 25 (2011) 20-29.

24. $\quad$ S.M. Krane. Amino Acids 35 (2008) 703-710.

25. G. Rohman,J. Spadavecchia. Nanomater. Regen. Med.(2016) 49-92.

26. J.P. Chen,C.H. Su. Acta Biomater. 7 (2011) 234-243.

27. L. Maleknia,Z.R. Majdi. Orient. J. Chem. 30 (2014) 2043-2048.

28. M. Erencia, F. Cano. J. Appl. Polym. Sci. 132 (2015) 1-11.

29. N.E. Zander, J.A. Orlicki. Biointerphases 5 (2010) 149-158.

30. H. Koh, T. Yong. Biomaterials 29 (2008) 3574-3582.

31. R.A. Neal, S.G. McClugage III. Tissue Eng. Part C Methods 15 (2008) 11-21.

32. S.H. Lim,H.-Q. Mao. Adv. Drug Deliv. Rev. 61 (2009) 1084-1096. 
33. P. Cools, R. Ghobeira. Plasma Science and Technology-Progress in Physical States and Chemical Reactions, Intech, Rijeka, Croatia, 2016, p. 201.

34. M.P. Prabhakaran, J. Venugopal. Nanotechnology 19 (2008) 1-8.

35. S. Agarwal, J.H. Wendorff. Polymer 49 (2008) 5603-5621.

36. D. Kai, S.S. Liow. Mater. Sci. Eng. C 45 (2014) 659-670.

37. L.S. Nair,C.T. Laurencin. Prog. Polym. Sci. 32 (2007) 762-798.

38. J.A. Hubbell. Curr. Opin. Biotechnol. 14 (2003) 551-558.

39. L.S. Nair, C.T. Laurencin. Prog. Polym. Sci. 32 (2007) 762-798.

40. A. Göpferich. Macromolecules 30 (1997) 2598-2604.

41. N. De Geyter,R. Morent. Biomedical Science, Engineering and Technology, Intech, Rijeka, Croatia, 2012, p. 225.

42. P.B. Maurus,C.C. Kaeding. Oper. Tech. Sports Med. 12 (2004) 158-160.

43. R. Morent, N. De Geyter. Plasma Process. Polym. 8 (2011) 171-190.

44. Y. Dong, T. Yong. Tissue Eng. Part A 16 (2009) 283-298.

45. K. Ceonzo, A. Gaynor. Tissue Eng. 12 (2006) 301-308.

46. J. Otto, M. Binnebösel. J. Invest. Surg. 23 (2010) 190-196.

47. R.M. Rasal, A.V. Janorkar. Prog. Polym. Sci. 35 (2010) 338-356.

48. J.C. Middleton,A.J. Tipton. Biomaterials 21 (2000) 2335-2346.

49. E. Fukada. IEEE Trans. Ultrason. Ferroelectr. Freq. Control 47 (2000) 1277-1290.

50. C. Ribeiro, J. Pärssinen. J. Biomed. Mater. Res. A 103 (2015) 2172-2175.

51. D. Garlotta. J. Polym. Environ. 9 (2001) 63-84.

52. R. Casasola, N.L. Thomas. Polymer 55 (2014) 4728-4737.

53. E. Zhang, C. Zhu. Mater. Sci. Eng. C 58 (2016) 278-285.

54. H. Xu, W. Cui. J. Appl. Polym. Sci. 127 (2013) 1550-1554.

55. X. Qiao, S.J. Russell. J. Funct. Biomater. 6 (2015) 667-686.

56. Z. Pan,J. Ding. Interface Focus 2 (2012) 366-377.

57. E.H. GANG, C.S. KI. FIBER. Polym. 13 (2012) 685-691.

58. H.K. Makadia,S.J. Siegel. Polymers 3 (2011) 1377-1397.

59. H.J. Shin, C.H. Lee. J. Biomater. Sci. Polym. Ed. 17 (2006) 103-119.

60. M. Therin, P. Christel. Biomaterials 13 (1992) 594-600.

61. K.A. Athanasiou, J. Schmitz. Tissue Eng. 4 (1998) 53-63.

62. M.A. Woodruff, D.W. Hutmacher. Prog. Polym. Sci. 35 (2010) 1217-1256.

63. A. Cipitria, A. Skelton. J. Mater. Chem. 21 (2011) 9419-9453.

64. L. Van der Schueren, B. De Schoenmaker. Eur. Polym. J. 47 (2011) 1256-1263.

65. K. Lee, H. Kim. Polymer 44 (2003) 1287-1294.

66. W.-J. Li, J.A. Cooper. Acta Biomater. 2 (2006) 377-385.

67. M. Abedalwafa, F. Wang. Rev. Adv. Mater. Sci. 34 (2013) 123-140.

68. S.L. Tao, T.A. Desai. Nano Lett. 7 (2007) 1463-1468.

69. D.A.E. Rollings, S. Tsoi. Langmuir 23 (2007) 5275-5278.

70. A. Yari, S. Teimourian. Adv. Biomed. Res. 5 (2016) 1-8.

71. H. Chen, R. Truckenmuller. Nanomaterials in Tissue Engineering: Fabrication and Applications, Woodhead, Sawston, England, 2013, p. 158.

72. D.H. Reneker, I. Chun. Nanotechnology 7 (1996) 216-223.

73. J. Doshi, D.H. Reneker. J. Electrostat. 35 (1995) 151-160.

74. K. Park, H.J. Jung. Macromol. Res. 14 (2006) 552-558.

75. A. Haider, S. Haider. Arab. J. Chem. (2015) 1-24.

76. N. Binulal, M. Deepthy. Tissue Eng. Part A 16 (2010) 393-404.

77. J. Wang, R. Ye. J. Biomed. Mater. Res. A 100 (2012) 632-645. 
78. F. Yang, R. Murugan. Biomaterials 26 (2005) 2603-2610.

79. D.I. Braghirolli, D. Steffens. J. Biomed. Mater. Res. Part B Appl. Biomater. 102 (2014) 700-708.

80. M. Khayet. J. Mater. Sci. Nanotechnol. 1 (2013) 1-4.

81. Z. Li, C. Wang. One-Dimensional Nanostructures, Springer, Berlin Heidelberg, Germany, 2013, p. 15.

82. C. Ru, F. Wang,. ACS Appl. Mater. Interfaces 7 (2015) 10872-10877.

83. H. Fong, I. Chun. Polymer 40 (1999) 4585-4592.

84. D.S. Katti, K.W. Robinson. J. Biomed. Mater. Res. Part B Appl. Biomater. 70 (2004) 286-296.

85. H.S. Kim, K. Kim. Macromol. Symp. 224 (2005) 145-154.

86. W. Liu, S. Thomopoulos. Adv. Healthc. Mater. 1 (2012) 10-25.

87. A. Martins, E.D. Pinho. Small 5 (2009) 1195-1206.

88. Y.-P. Jiao, F.-Z. Cui. Biomed. Mater. 2 (2007) R24-R37.

89. M.H. Ho, J.J. Lee, Macromol. Biosci. 7 (2007) 467-474.

90. G.-H. Koo, J. Jang. Fiber. Polym. 9 (2008) 674-678.

91. $\quad$ S.C. J. Loo, C.P. Ooi. Polym. Degrad. Stab. 83 (2004) 259-265.

92. Y. Zhu, C. Gao. Biomacromolecules 3 (2002) 1312-1319.

93. T.I. Croll, A.J. O'Connor. Biomacromolecules 5 (2004) 463-473.

94. Y. Zhu, M.F. Leong. Biomaterials 28 (2007) 861-868.

95. M. Chong, C. Lee. Mater. Sci. Eng. C 27 (2007) 309-312.

96. J.M. Goddard, J. Hotchkiss. Prog. Polym. Sci. 32 (2007) 698-725.

97. S.M. Desai, R. Singh. Long Term Properties of Polyolefins, Springer, Berlin Heidelberg, Germany, 2004, p. 231.

98. L. Ghasemi-Mobarakeh, M.P. Prabhakaran. Biomaterials 29 (2008) 4532-4539.

99. W. He, T. Yong. Tissue Eng. 11 (2005) 1574-1588.

100. K. E. Swindle-Reilly, C. S. Paranjape. Prog. Biomater. 3 (2014) 1-8.

101. M.P. Prabhakaran, J.R. Venugopal. Tissue Eng. Part A 14 (2008) 1787-1797.

102. R.A. Neal, S.S. Tholpady. J. Biomed. Mater. Res. A 100 (2012) 406-423.

103. H.W. Kim, H.S. Yu. J. Biomed. Mater. Res. A 87 (2008) 25-32.

104. E. Seyedjafari, M. Soleimani. Biomacromolecules 11 (2010) 3118-3125.

105. D. Gupta, J. Venugopal. Biomaterials 30 (2009) 2085-2094.

106. G. Sui, X. Yang. J. Biomed. Mater. Res. A 82 (2007) 445-454.

107. J. Bockelmann, K. Klinkhammer. Tissue Eng. Part A 17 (2010) 475-486.

108. C. Cohn, S. Leung. Express Polym. Lett. 10 (2016) 430-437.

109. G. Jin, M.P. Prabhakaran. Acta Biomater. 7 (2011) 3113-3122.

110. D.I. Zeugolis, S.T. Khew. Biomaterials 29 (2008) 2293-2305.

111. L. Yang, C.F.C. Fitié. Biomaterials 29 (2008) 955-962.

112. A.G. Guex, A. Frobert. Acta Biomater. 10 (2014) 2996-3006.

113. K. Wulf, M. Teske. J. Biomed. Mater. Res. Part B Appl. Biomater. 98 (2011) 89-100.

114. M. Domingos, F. Intranuovo. Acta Biomater. 9 (2013) 5997-6005.

115. H. Shen, X. Hu. Biomaterials 28 (2007) 4219-4230.

116. H. Park, K.Y. Lee. Macromol. Res. 15 (2007) 238-243.

117. M. Zelzer, D. Scurr. J. Phys. Chem. B 113 (2009) 8487-8494.

118. N. Guerrouani. A. Baldo, J. Appl. Polym. Sci. 105 (2007) 1978-1986.

119. A.G. Guex, D. Hegemann. Colloids Surf. B Biointerfaces 123 (2014) 724-733.

120. Z.W. Ma, W. He. Tissue Eng. 11 (2005) 1149-1158. 
121. Z. Cheng, S.-H. Teoh. Biomaterials 25 (2004) 1991-2001.

122. J. Shi, L. Wang. ACS Appl. Mater. Interfaces 2 (2010) 1025-1030.

123. E. Schnell, K. Klinkhammer. Biomaterials 28 (2007) 3012-3025.

124. C. He, X. Xu. J. Biomed. Mater. Res. A 97 (2011) 339-347.

125. S. Heydarkhan-Hagvall, K. Schenke-Layland. Biomaterials 29 (2008) 2907-2914.

126. G. Wang, X. Hu. In Vitro Cell. Dev. Biol.-Anim. 47 (2011) 234-240.

127. C. Spadaccio, A. Rainer. J. Cell. Mol. Med. 15 (2011) 1096-1108.

128. M.P. Prabhakaran, J. Venugopal. Acta Biomater. 5 (2009) 2884-2893.

129. H.S. Yoo, T.G. Kim. Adv. Drug Deliv. Rev. 61 (2009) 1033-1042.

130. I. Langmuir. Proc. Natl. Acad. Sci. 14 (1928) 627-637.

131. F.S. Denes,S. Manolache. Prog. Polym. Sci. 29 (2004) 815-885.

132. P. Cools, N. De Geyter. Advances in bioengineering, Intech, Rijeka, Croatia, 2015, p. 117.

133. A. Bogaerts, E. Neyts. Spectrochim. Acta Part B At. Spectrosc. 57 (2002) 609-658.

134. D.B. Graves,M.J. Kushner. J. Vac. Sci. Technol., A 21 (2003) S152-S156.

135. T. Desmet, R. Morent. Biomacromolecules 10 (2009) 2351-2378.

136. N. De Geyter, R. Morent. Surf. Coat. Technol. 201 (2007) 7066-7075.

137. J.M. Corey, C.C. Gertz. Acta Biomater. 4 (2008) 863-875.

138. K. Webb, V. Hlady. J. Biomed. Mater. Res. 41 (1998) 422.

139. J.H. Lee, G. Khang. J. Colloid Interface Sci. 205 (1998) 323-330.

140. D. Yan, J. Jones. J. Med. Biol. Eng. 33 (2013) 171-178.

141. Z. Gugala,S. Gogolewski. J. Biomed. Mater. Res. A 76 (2006) 288-299.

142. R. Latkany, A. Tsuk. J. Biomed. Mater. Res. 36 (1997) 29-37.

143. W. Cui, X. Li. Polym. Degrad. Stab. 93 (2008) 731-738.

144. L.S. Dolci, S.D. Quiroga. Plasma Process. Polym. 11 (2014) 203-213.

145. K. Fujihara, M. Kotaki. Biomaterials 26 (2005) 4139-4147.

146. J. Venugopal, S. Low. J. Biomed. Mater. Res. A 85A (2008) 408-417.

147. D. Hegemann, H. Brunner. Nucl. Instrum. Methods Phys. Res. B 208 (2003) 281-286.

148. R. Morent, N. De Geyter. Plasma Chem. Plasma Process. 30 (2010) 525-536.

149. J. Venugopal, S. Low. J. Biomed. Mater. Res. A 85 (2008) 408-417.

150. D. Sankar, K.T. Shalumon. Tissue Eng. Part A 20 (2014) 1689-1702.

151. H.J. Jeon, H. Lee. Plasma Process. Polym. 11 (2014) 142-148.

152. H. Jahani, S. Kaviani. Cell J. 14 (2012) 31-38.

153. S. de Valence, J.C. Tille. Eur. J. Pharm. Biopharm. 85 (2013) 78-86.

154. N. Abbasi, S. Soudi. Cell J. 16 (2014) 245-254.

155. S. Sharma, D. Gupta. Invest. Ophthalmol. Vis. Sci. 55 (2014) 899-907.

156. A.M. Pappa, V. Karagkiozaki. Beilstein J. Nanotechnol. 6 (2015) 254-262.

157. N. Recek, M. Resnik. Int. J. Polym. Sci. 2016 (2016) 1-9.

158. S. Surucu, H. Turkoglu Sasmazel. J. Biomater. Sci. Polym. Ed. 27 (2016) 111-132.

159. W. Liu, J.C. Zhan. Colloids Surf. B Biointerfaces 113 (2014) 101-106.

160. D.M. Correia, C. Ribeiro. Appl. Surf. Sci. 371 (2016) 74-82.

161. Q. Cheng, B.L.P. Lee. Tissue Eng. Part A 19 (2013) 1188-1198.

162. W.T. Liu, Q. Cai. J. Bioact. Compat. Polym. 28 (2013) 453-467.

163. K.E. Park, K.Y. Lee. Macromol. Symp. 249 (2007) 103-108.

164. H. Park, J.W. Lee. Colloids Surf. B Biointerfaces 77 (2010) 90-95. 
165. N. Inagaki. Plasma Surface Modification and Plasma Polymerization, CRC Press, Pennysylvania, United States, 1996.

166. Y.M. Ko, D.Y. Choi. J. Nanosci. Nanotechnol. 15 (2015) 192-195.

167. K. Park, Y.M. Ju. J. Biomater. Sci. Polym. Ed. 18 (2007) 369-382.

168. B. Jarrell, S. Williams. Surgery 100 (1986) 392-399.

169. M. Deutsch, J. Meinhart. Surgery 126 (1999) 847-855.

170. W. He, Z.W. Ma. Biomaterials 26 (2005) 7606-7615.

171. F. Yang, J.G.C. Wolke. Chem. Eng. J. 137 (2008) 154-161.

172. N.E. Zander, J.A. Orlicki. ACS Appl. Mater. Interfaces 4 (2012) 2074-2081.

173. J. Jia, Y.Y. Duan. J. Biomed. Mater. Res. A 86A (2008) 364-373.

174. R. Safaeijavan, M. Soleimani. J. Paramed. Sci. 5 (2013) 67-73.

175. N.J. Schaub, C. Le Beux. Plos One 10 (2015) 1-19.

176. J.R.J. Paletta, S. Bockelmann. J. Mater. Sci. Mater. Med. 21 (2010) 1363-1369.

177. M. Ghaedi, M. Soleimani. Cell. Mol. Biol. Lett. 17 (2012) 89-106.

178. H.J. Seo, M.H. Lee. J. Appl. Phys. 114 (2013) 1-6.

179. B.J. Park, H.J. Seo. Surf. Coat. Technol. 205 (2010) S222-S226.

180. K.A. Meade, K.J. White. J. Biol. Chem. 288 (2013) 5530-5538. 